medRxiv preprint doi: https://doi.org/10.1101/2021.09.15.21263521; this version posted September 22, 2021. The copyright holder for this preprint (which was not certified by peer review) is the author/funder, who has granted medRxiv a license to display the preprint in perpetuity.

It is made available under a CC-BY-NC-ND 4.0 International license .

\title{
1 Design and implementation of multiplexed amplicon sequencing panels to serve genomic \\ 2 epidemiology of infectious disease: a malaria case study
}

3 Emily LaVerriere ${ }^{1,2 \pi}$, Philipp Schwabl ${ }^{1,2 \pi}$, Manuela Carrasquilla ${ }^{1,2,3 \pi}$, Aimee R. Taylor ${ }^{2,4}$, Zachary M.

4 Johnson $^{1,2}$, Meg Shieh ${ }^{1,2}$, Ruchit Panchal ${ }^{1,2}$, Timothy J. Straub ${ }^{1,2}$, Rebecca Kuzma ${ }^{1,2}$, Sean Watson ${ }^{1}$,

5 Caroline O. Buckee ${ }^{4}$, Carolina M. Andrade ${ }^{5}$, Silvia Portugal ${ }^{3,5}$, Peter D. Crompton ${ }^{6}$, Boubacar Traore ${ }^{7}$,

6 Julian C. Rayner ${ }^{8}$, Vladimir Corredor ${ }^{9}$, Kashana James $^{10}$, Horace Cox ${ }^{11}$, Angela M. Early ${ }^{1,2}$, Bronwyn

7 L. Maclnnis ${ }^{2}$, Daniel E. Neafsey ${ }^{1,2^{*}}$

8 Affiliations:

$9{ }^{1}$ Department of Immunology and Infectious Diseases, Harvard T.H. Chan School of Public Health,

10 Boston, MA, USA.

112 Infectious Disease and Microbiome Program, Broad Institute of MIT and Harvard, Cambridge, MA,

12 USA.

$13{ }^{3}$ Max Planck Institute for Infection Biology, Berlin, Germany.

$14{ }^{4}$ Department of Epidemiology, Harvard T.H. Chan School of Public Health, Boston, MA, USA.

$15{ }^{5}$ Centre of Infectious Diseases, Parasitology, Heidelberg University Hospital, Heidelberg, Germany.

$16{ }^{6}$ Malaria Infection Biology and Immunity Section, Laboratory of Immunogenetics, National Institute of

17 Allergy and Infectious Diseases, National Institutes of Health, Rockville, MD 20852, USA

187 Mali International Center of Excellence in Research, University of Sciences, Technique and Technology

19 of Bamako, BP 1805, Point G, Bamako, Mali.

$20{ }^{8}$ Cambridge Institute for Medical Research, University of Cambridge, Cambridge CB2 OXY, United

21 Kingdom

$22{ }^{9}$ Departamento de Salud Pública, Facultad de Medicina, Universidad Nacional de Colombia, Bogotá,

23 Colombia

$24{ }^{10}$ Guyana National Malaria Control Program, Ministry of Health, 0592 Georgetown, Guyana

$25{ }^{11}$ Guyana Vector Control Services, Ministry of Health, 0592 Georgetown, Guyana

26 I These authors contributed equally to this work.

27 * Corresponding author. Email: neafsey@hsph.harvard.edu

28 Keywords: malaria, genotyping, genome, epidemiology, relatedness, amplicon sequencing

\section{Abstract} cost-effective monitoring of threatened species and managed wildlife populations, and shows strong

32 potential for genomic epidemiology of infectious disease. AmpSeq data for infectious microbes can

33 inform disease control in multiple ways, including measuring drug resistance marker prevalence,

34 distinguishing imported from local cases, and determining the effectiveness of therapeutics. We describe 
medRxiv preprint doi: https://doi.org/10.1101/2021.09.15.21263521; this version posted September 22, 2021. The copyright holder for this

preprint (which was not certified by peer review) is the author/funder, who has granted medRxiv a license to display the preprint in perpetuity.

It is made available under a CC-BY-NC-ND 4.0 International license .

35 the design and comparative evaluation of two new AmpSeq assays for Plasmodium falciparum malaria

36 parasites: a four-locus panel ('4CAST') composed of highly diverse antigens, and a 129-locus panel

37 ('AMPLseq') composed of drug resistance markers, highly diverse loci for measuring relatedness, and a

38 locus to detect Plasmodium vivax co-infections. We explore the performance of each panel in various

39 public health use cases with in silico simulations as well as empirical experiments. We find that the

40 smaller 4CAST panel performs reliably across a wide range of parasitemia levels without DNA

41 pre-amplification, and could be highly informative for evaluating the number of distinct parasite strains

42 within samples (complexity of infection), and distinguishing recrudescent infections from new infections in

43 therapeutic efficacy studies. The AMPLseq panel performs similarly to two existing panels of comparable

44 size for relatedness measurement, despite differences in the data and approach used for designing each

45 panel. Finally, we describe an R package (paneljudge) that facilitates design and comparative evaluation

46 of AmpSeq panels for relatedness estimation, and we provide general guidance on the design and

47 implementation of AmpSeq panels for genomic epidemiology of infectious disease.

\section{Introduction}

49

Genetic data are a valuable resource for understanding the epidemiology of infectious disease.

50 The value of this data type has been highlighted by the COVID-19 pandemic, for which viral sequence

51 analysis has greatly informed patterns of disease spread and evolution, influencing public health policy

52 decisions around the world (Oude Munnink et al., 2021). Applications of genetic data in epidemiology

53 extend from viral and bacterial outbreak management (Baker, Thomson, Weill, \& Holt, 2018; Coll et al.,

54 2017; Quick et al., 2016) to the study of eukaryotic parasites underlying important diseases such as

55 malaria, toxoplasmosis, helminthiasis, leishmaniasis and Chagas disease.

56 Many use cases (applications) of genetic data have been identified for malaria (Dalmat,

57 Naughton, Kwan-Gett, Slyker, \& Stuckey, 2019), the leading parasitic killer worldwide (WHO, 2019),

58 include tracking the spread of drug/insecticide resistance genetic markers and diagnostic resistance

59 mutations (Chenet et al., 2016; Jacob et al., 2021; Kayiba et al., 2021; Lautu-Gumal et al., 2021; Miotto

60 et al., 2020), assessing disease transmission levels (Daniels et al., 2015; Galinsky et al., 2015), 
medRxiv preprint doi: https://doi.org/10.1101/2021.09.15.21263521; this version posted September 22, 2021. The copyright holder for this

preprint (which was not certified by peer review) is the author/funder, who has granted medRxiv a license to display the preprint in perpetuity.

It is made available under a CC-BY-NC-ND 4.0 International license .

61 identifying sources of infections and imported cases (Liu et al., 2020; Tessema et al., 2019), and

62 estimating genetic connectivity among different populations (Taylor et al., 2017). Malaria parasite genetic

63 data also have demonstrated utility in therapeutic efficacy studies, for distinguishing recrudescent

64 infections potentially indicative of low drug efficacy from reinfections or relapses from dormant liver

65 stages (Gruenberg, Lerch, Beck, \& Felger, 2019; Jones et al., 2021). In the malaria field, these

66 applications are served by different types of genetic data produced at varying resolution, technical

67 complexity, and cost, ranging from genetic panels that may comprise as few as $8-12$ polymorphic

68 microsatellites (MS) or 24 single nucleotide polymorphisms (SNPs) (Baniecki et al., 2015; Daniels et al.,

69 2008), to whole genome sequencing (WGS) data (Miotto et al., 2015; Takala-Harrison et al., 2015).

To be scalable and sustainable, genetic data should be produced at the minimum resolution that

71 provides robust support for the intended analysis application. Whole genome sequencing (WGS) data

72 provide the most complete population genomic perspective on an organism of interest. However, the cost

73 and technical challenges of generating, storing, and interpreting WGS data are impediments to scalability

74 and widespread implementation for organisms with large genomes, or microbes with small genomes in

75 samples dominated by host DNA. Targeted sequencing approaches that focus deep coverage on select

76 genomic regions of interest using multiplexed PCR amplification (AmpSeq) are finding increased

77 application in conservation genomics and fisheries biology (Baetscher, Clemento, $\mathrm{Ng}$, Anderson, \&

78 Garza, 2018; Hargrove, McCane, Roth, High, \& Campbell, 2021; Natesh et al., 2019; Schmidt, Campbell,

79 Govindarajulu, Larsen, \& Russello, 2020), and can serve genomic epidemiology of infectious diseases by

80 focusing sequencing coverage on the most informative regions of pathogen or parasite genomes, instead

81 of typically dominant host genomes (Jacob et al., 2021; Tessema et al., 2020).

Recent work on AmpSeq protocols for genotyping malaria and trypanosomatid parasites has

83 confirmed the viability of this approach with low-parasitemia host and vector samples, where parasite

84 DNA comprises a very small fraction of the total sample (Jacob et al., 2021; Schwabl et al., 2020;

85 Tessema et al., 2020). Furthermore, one recent study has confirmed the value of designing amplicons to

86 capture multi-SNP 'microhaplotypes', which exhibit polyallelic rather than biallelic diversity to facilitate

87 relatedness inference (Tessema et al., 2020). New relatedness-based analytical approaches for genomic 
medRxiv preprint doi: https://doi.org/10.1101/2021.09.15.21263521; this version posted September 22, 2021. The copyright holder for this

preprint (which was not certified by peer review) is the author/funder, who has granted medRxiv a license to display the preprint in perpetuity.

It is made available under a CC-BY-NC-ND 4.0 International license .

88 epidemiology are currently developing for malaria parasites and other sexually recombining pathogens

89 (Henden, Lee, Mueller, Barry, \& Bahlo, 2018; Schaffner, Taylor, Wong, Wirth, \& Neafsey, 2018). The use

90 of genomic data for estimation of recent common ancestry shared by pairs or clusters of parasites or

91 mosquitoes has shown strong potential to provide epidemiologically useful inferences over very small

92 geographic distances (10s-100s of kilometers) and short time scales (weeks to months) relative to

93 traditional population genetic parameters of population diversity and divergence (Cerqueira et al., 2017;

94 Taylor et al., 2017). While many analyses of recent common ancestry in malaria parasites to date have

95 used WGS data, targeted genotyping of as few as 200 biallelic SNPs or 100 polyallelic loci (e.g.,

96 microsatellites or microhaplotypes) may also be used to infer recent common ancestry with necessary

97 precision (Taylor, Jacob, Neafsey, \& Buckee, 2019), making AmpSeq an excellent candidate to serve

98 relatedness estimation.

However, there remains uncertainty in the molecular epidemiology field as to the suitability of

100

existing panels for profiling parasite or pathogen populations in specific geographic locations that did not

101 inform the original panel designs, and it is unclear which protocol features are most conducive to

102 implementation in both high and low resource settings. Should each disease field adopt a common

103 multiplexed amplicon protocol and panel, or should bespoke panels be implemented regionally to

104 address genetically distinct parasite populations and specific use cases?

105 To address these questions, in this manuscript we describe the design and comparative

106 evaluation of two new multiplexed amplicon assays for Plasmodium falciparum malaria parasites: a

107 four-locus panel composed of highly diverse loci, ideal for estimating the number of genetically distinct

108 strains within an infection (Complexity of Infection; COI) as well as distinguishing pre-existing vs. new

109 infections in any geographic setting, and a 129-locus panel composed of drug resistance markers and

110 many diverse loci for relatedness inference designed for application in South America (a region that did

111 not inform previously published panel designs) as well as other geographic regions. Both assays use

112 non-proprietary reagents (including standard PCR oligos) in order to maximize accessibility and

113 affordability in malaria-endemic regions. The panels are supported by new open-source bioinformatic

114 analysis pipelines to facilitate widespread use. We also show that the core sets of multiplexed PCR 
medRxiv preprint doi: https://doi.org/10.1101/2021.09.15.21263521; this version posted September 22, 2021. The copyright holder for this preprint (which was not certified by peer review) is the author/funder, who has granted medRxiv a license to display the preprint in perpetuity.

It is made available under a CC-BY-NC-ND 4.0 International license .

115 oligos can flexibly accommodate most new targets not included in the original design, allowing for panel

116 customization towards detecting locally relevant resistance markers, polymorphic loci, and co-infecting

117 parasite species. We use whole genome sequencing data to explore the degree to which our newly

118 described and previously published genotyping panels can serve studies in diverse geographies, versus

119 the alternative of customizing panels with targets that are locally informative but not globally useful. We

120 suggest there is value in genotyping panels that can be flexibly adapted to incorporate informative

121 targets from pathogen populations of interest. The analyses and resources described in this manuscript

122 clarify the rapidly diversifying options for targeted microbial sequencing (Fig. 1), by providing tools and

123 guidance for the comparative evaluation and refinement of AmpSeq panels.

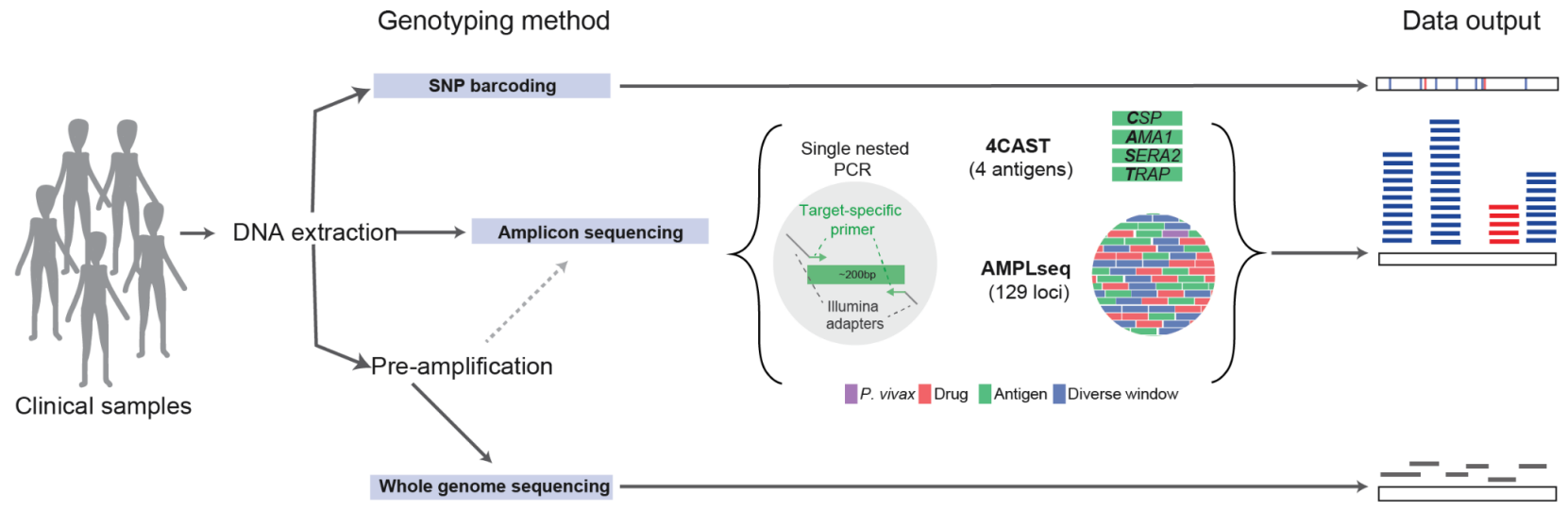

124 Figure 1. Amplicon sequencing and other genotyping approaches for genomic epidemiology of

125 infectious diseases.

126 Schematic of three common approaches for molecular surveillance data generation. Genomic DNA can

127 be extracted from clinical samples and then processed using any of the three methods shown: SNP

128 barcoding, amplicon sequencing, or whole genome sequencing (WGS). Our two amplicon panels,

129 AMPLseq and 4CAST, are shown, with representations of their loci and amplification. Pre-amplification

130 (selective whole genome amplification), which increases the ratio of parasite to human DNA in samples,

131 is generally recommended for WGS and some amplicon sequencing panels (AMPLseq, but not 4CAST).

132 SNP barcoding provides data in the form of variant calls at each SNP; amplicon sequencing provides

133 extremely deep coverage at select, small regions of the genome; and WGS generally provides shallower

134 coverage of the entire genome.

\section{Materials and Methods}


medRxiv preprint doi: https://doi.org/10.1101/2021.09.15.21263521; this version posted September 22, 2021. The copyright holder for this

preprint (which was not certified by peer review) is the author/funder, who has granted medRxiv a license to display the preprint in perpetuity.

It is made available under a CC-BY-NC-ND 4.0 International license.

\section{Panel designs}

137

We developed a small multiplex of four highly polymorphic antigenic loci, dubbed '4CAST': CSP,

138 AMA1, SERA2, and TRAP (Fig. 2). All four amplicons use previously published primer sequences (Miller

139 et al., 2017; Neafsey et al., 2015), as no modification was required for successful multiplexing.

140 In designing the larger 'AMPLseq' multiplexed amplicon panel, we first built a large pool of

141 candidate loci, anticipating significant attrition of candidates due to primer incompatibility. We prioritized

142 four classes of loci: loci within antigens of interest (Helb et al., 2015), loci with high population diversity

143 for relatedness inference (Taylor et al., 2019), loci included in the SpotMalaria v1 panel (Chang et al.,

144 2019; Jacob et al., 2021), and known drug resistance markers. We contracted the services of GTseek

145 LLC (https://gtseek.com) to design multiplexed oligo panels according to the criteria previously described

146 for the Genotyping-in-Thousands by sequencing (GT-seq) protocol (Campbell, Harmon, \& Narum, 2015)

147 (S1 Supporting information). We optimized the final primer set and and reaction conditions through

148 several sequencing runs and determined that the primers for the four 4CAST loci (CSP, AMA1, SERA2,

149 TRAP) could be added to the panel without impacting amplification of the other loci. We also successfully

150 added primers amplifying known markers of antimalarial drug resistance within the genes dhfr, dhps,

151 mdr1, and kelch13 (S2 Table). Furthermore, we successfully added previously described primers for

152 PvDHFR (Lefterova, Budvytiene, Sandlund, Färnert, \& Banaei, 2015) in order to identify P. falciparum / P.

153 vivax co-infections that have gone undetected in preliminary screening by microscopy or rapid diagnostic

154 test (RDT). The final panel, dubbed 'AMPLseq' (short for Assorted Mix of Plasmodium Loci) contains this

155 single P. vivax locus and 128 P. falciparum loci (Fig. 2), with a median length across all amplicons of 276

156 bp (S1 Fig.). 
medRxiv preprint doi: https://doi.org/10.1101/2021.09.15.21263521; this version posted September 22, 2021. The copyright holder for this preprint (which was not certified by peer review) is the author/funder, who has granted medRxiv a license to display the preprint in perpetuity.

It is made available under a CC-BY-NC-ND 4.0 International license .

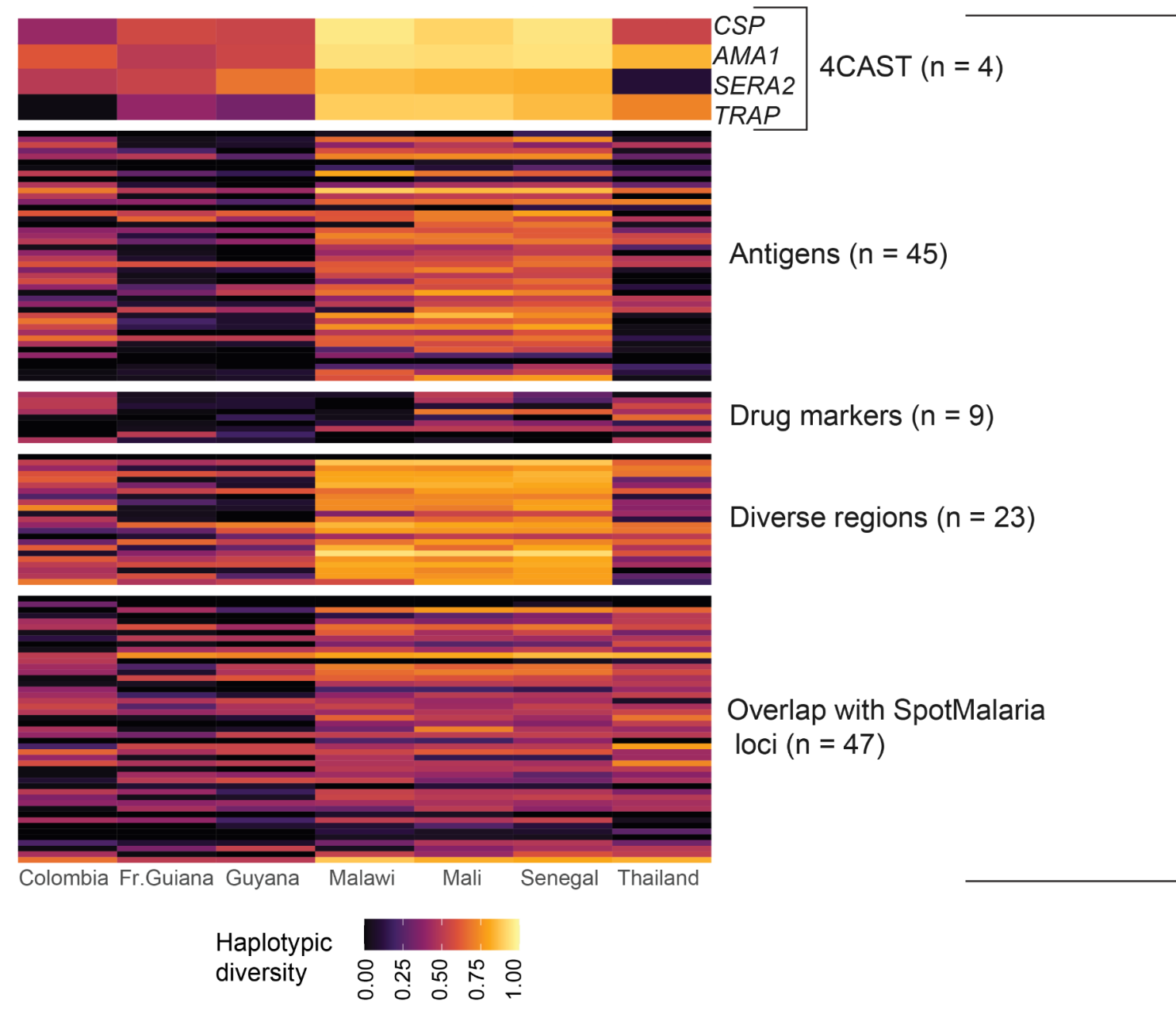

AMPLseq

157 Figure 2. Global characterization of loci in the 4CAST and AMPLseq panels.

158 Estimates of diversity of each locus in the 4CAST and AMPLseq panels, with one locus per row. We 159 estimated haplotypic diversity from monoclonal $P$. falciparum WGS data from each country. The top 4 loci 160 shown represent the 4CAST loci, which are also included in the AMPLseq panel. All 128 P. falciparum

161 loci in the AMPLseq panel are shown; the single $P$. vivax locus is not shown.

\section{Panel protocols}

164 Table) and diluted the combined primer mix to $6.25 \mu \mathrm{M}$ per primer in nuclease-free water $\left(\mathrm{NF}^{\mathrm{d}} \mathrm{H}_{2} \mathrm{O}\right)$.

165 Each $10.5 \mu$ I PCR1 reaction incorporated $1.5 \mu$ l combined primer mix, $5 \mu$ KAPA HiFi HotStart ReadyMix

166 (2x), and $4 \mu \mathrm{l}$ sample template. PCR1 amplification consisted of an initial incubation step at $95^{\circ} \mathrm{C}(3$

$167 \mathrm{~min}) ; 25$ amplification cycles at $95^{\circ} \mathrm{C}(20 \mathrm{~s}), 57^{\circ} \mathrm{C}(15 \mathrm{~s})$ and $62{ }^{\circ} \mathrm{C}(30 \mathrm{~s})$; and a final extension step at

$16872^{\circ} \mathrm{C}(1 \mathrm{~min})$. Each $12.2 \mu \mathrm{l} \mathrm{PCR} 2$ reaction (which adds sample indices and sequencing adapters)

169 incorporated $2.2 \mu$ l unique dual index (10 $\mu \mathrm{M}$ Illumina Nextera DNA UD Indexes), $5 \mu \mathrm{KAPA} \mathrm{HiFi}$

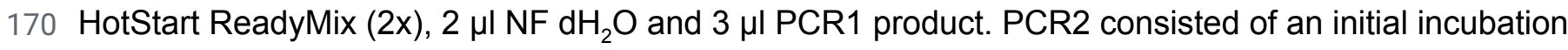


medRxiv preprint doi: https://doi.org/10.1101/2021.09.15.21263521; this version posted September 22, 2021. The copyright holder for this

preprint (which was not certified by peer review) is the author/funder, who has granted medRxiv a license to display the preprint in perpetuity.

It is made available under a CC-BY-NC-ND 4.0 International license .

171 step at $95^{\circ} \mathrm{C}(1 \mathrm{~min}) ; 10$ amplification cycles at $95^{\circ} \mathrm{C}(15 \mathrm{~s}), 55^{\circ} \mathrm{C}(15 \mathrm{~s})$ and $72{ }^{\circ} \mathrm{C}(30 \mathrm{~s})$; and a final

172 extension step at $72{ }^{\circ} \mathrm{C}(1 \mathrm{~min})$. We combined PCR2 products in equal volumes and performed

173 double-sided size selection using Agencourt AMPure XP beads (Beckman Coulter): we incubated $100 \mu$ I

174 library with $55 \mu$ l beads, immobilized beads via magnet rack, and transferred the supernatant to a new

175 tube. We incubated the transferred supernatant with $20 \mu$ l beads and washed immobilized beads twice

176 with $80 \%$ ethanol. We eluted the library in $25 \mu$ I EB buffer (10 mM Tris- $\mathrm{Cl}, \mathrm{pH} 8.5)$, subsequently adding

$1772.5 \mu \mathrm{l}$ EB buffer with 1\% Tween-20. We verified size selection via Agilent BioAnalyzer 2100 and

178 sequenced the selected library at $6 \mathrm{pM}$ with $>10 \%$ PhiX in paired-end, 500-cycle format using MiSeq

179 Reagent Kit v2 (S1 Protocol).

We followed a similar nested PCR and pooled clean-up procedure for AMPLseq library

181 construction. Primer sequences, input volumes and concentrations are listed in S3 Table and PCR

182 conditions and size selection steps are shown in S2 Protocol. As detailed therein, library construction for

183 AMPLseq library construction differs in a few minor aspects. For example, primer input quantities vary

184 slightly (800 pmol +/- 33\%) to account for amplification rate differences among loci. PCR1 products are

185 diluted 1:12 in NF $\mathrm{dH}_{2} \mathrm{O}$ prior to PCR2 and only single-sided (left-tailed) bead-based size selection is

186 used to enhance yield. Sequencing also occurs via paired-end, 500-cycle MiSeq but with a higher final

187 library loading concentration (12 pM) and a lower fraction of PhiX (8\%).

\section{Mock samples}

We generated mock samples from parasite lines 3D7 and Dd2, cultured at 3\% hematocrit in

190 commercially obtained red blood cells as previously described (Trager \& Jensen, 1976). We extracted

191 genomic DNA using the Qiagen Blood and Tissue Kit on cells previously lysed with 0.15\% saponin. We

192 generated positive control template representing DNA extractions from whole human blood infected with

19310,000 monoclonal 3D7 parasites/ $\mu$ l by diluting genomic DNA from 3D7 to $0.25 \mathrm{ng} / \mu \mathrm{l}$ in $10 \mathrm{ng} / \mu \mathrm{l}$ human

194 genomic DNA, and storing in 10 mM Tris-HCl (pH 8.0), 1 mM EDTA (Promega, Madison, WI). We

195 generated further control templates representing 1000, 100, and 10 3D7 parasites/ $\mu$ l by serial 1:10

196 dilution of the 10,000 3D7 parasites/ $\mu$ l control, likewise using $10 \mathrm{ng} / \mu \mathrm{l}$ human genomic DNA as diluent. 
medRxiv preprint doi: https://doi.org/10.1101/2021.09.15.21263521; this version posted September 22, 2021. The copyright holder for this

preprint (which was not certified by peer review) is the author/funder, who has granted medRxiv a license to display the preprint in perpetuity.

It is made available under a CC-BY-NC-ND 4.0 International license .

197 We also generated a 10,000 parasites/ $\mu$ l positive control as described above but using Dd2 instead of

198 3D7 strain genomic DNA. We generated mixed-strain control templates by combining the 10,000 3D7

199 parasites/ $\mu \mathrm{l}$ control with this $10,000 \mathrm{Dd} 2$ parasites/ $\mu \mathrm{l}$ control at $1: 1,3: 1$, and 10:1 ratios (respectively).

200 We serially diluted the $1: 1$ ratio to 1000,100 , and 10 parasites/ $\mu /$ concentrations and diluted the $3: 1$ and

$20110: 1$ ratios to 1000 and 100 parasites/ $\mu$ l concentrations using $10 \mathrm{ng} / \mu \mathrm{l}$ human genomic DNA diluent as

202 before. We also applied selective whole genome amplification (sWGA) to all above control templates

203 representing $\leq 1000$ parasites/ $\mu$ l. The $50 \mu \mathrm{l}$ sWGA reaction followed Oyola et al. 2016 (Oyola et al.,

204 2016) with the exception of fixing template input volume to $10 \mu \mathrm{L}$. We purified sWGA products with

205 Agencourt AMPure XP beads (Beckman Coulter) on the KingFisher Flex (S3 Protocol) and verified

206 amplification success via NanoDrop (ThermoFisher Scientific).

\section{Clinical samples}

208 We tested the panels on clinical dried blood spot (DBS) samples from Mali and Guyana. Tran et

209 al. collected samples in Kalifabougou, Mali in 2011 - 2013 as previously described (Tran et al., 2013).

210 The Kalifabougou cohort study was approved by the Ethics Committee of the Faculty of Medicine,

211 Pharmacy and Dentistry at the University of Sciences, Technique and Technology of Bamako, and the

212 Institutional Review Board of the National Institute of Allergy and Infectious Diseases, National Institutes

213 of Health (NIH IRB protocol number: 11IN126; https://clinicaltrials.gov/; trial number NCT01322581).

214 Written informed consent was obtained from participants or parents or guardians of participating children

215 before inclusion in the study. The Guyana Ministry of Health collected samples from Port Kaituma and

216 Georgetown, Guyana between May - August 2020, by spotting participants' whole blood onto Whatman

217 FTA cards and storing the samples with individual desiccant packets at room temperature. Informed

218 consent (or parental assent for minors) was obtained for all subjects according to protocols approved by

219 ethical committees.

220 We punched DBS samples 3 - 5 times into a 96-well deep well plate using the DBS pneumatic

221 card puncher (Analytical Sales and Services, Inc.) equipped with a $3 \mathrm{~mm}$ cutter. We then extracted gDNA

222 following the DNA purification from buccal swab section of the KingFisher Ready DNA Ultra 2.0 Prefilled 
medRxiv preprint doi: https://doi.org/10.1101/2021.09.15.21263521; this version posted September 22, 2021. The copyright holder for this

preprint (which was not certified by peer review) is the author/funder, who has granted medRxiv a license to display the preprint in perpetuity.

It is made available under a CC-BY-NC-ND 4.0 International license .

223 Plates for KingFisher Flex instruments protocol (ThermoFisher Scientific) with minor modifications (S4

224 Protocol). We used the same sWGA procedure as above on the extracted gDNA.

\section{Whole genome sequencing and variant calling}

226 We performed whole genome sequencing on clinical samples collected in Guyana to validate

227 4CAST and AMPLseq outcomes. We performed sWGA on DNA samples as described above to enrich

228 parasite DNA. We used the enriched DNA to construct Illumina sequencing libraries from the amplified

229 material using the NEBNext Ultra II FS DNA prep kit (NEB \#E6177) prior to sequencing on an Illumina

230 HiSeqX instrument at the Broad Institute, using 150 bp paired-end reads, targeting a sequencing depth

231 of at least 50X coverage. We aligned reads to the $P$. falciparum $\mathrm{v}$ reference genome assembly using

232 BWA-MEM (Li, 2013) and called SNPs and INDELs using the GATK HaplotypeCaller (DePristo et al.,

233 2011; McKenna et al., 2010; Van der Auwera et al., 2013) according to the best practices for $P$.

234 falciparum as determined by the Pf3k consortium (https://www.malariagen.net/resource/34). Analyses

235 were limited to the callable segments of the genome (Miles et al., 2016) and excluded sites where over

$23620 \%$ of samples were multiallelic. Data from these samples were submitted to the NCBI Sequence Read

237 Archive (http://www.ncbi.nlm.nih.gov/sra) under accession PRJNA758191.

\section{Amplicon data analysis}

239 We developed an application named AmpSeQC (S2 Supporting information) to assess

240 sequence quality and amplicon/sequence run success (S2 Fig.). We also used AmpSeQC for $P$. vivax

241 detection by applying a concatenation of the $P$. falciparum 3D7 and $P$. vivax PvP01 reference genomes

242 during the BWA-MEM alignment step. For in-depth assessment of $P$. falciparum sequence variation, we

243 processed paired-end Illumina sequencing data in the form of FASTQ files using a custom analysis

244 pipeline (S2 Supporting information) that leverages the Divisive Amplicon Denoising Algorithm

245 (DADA2) tool designed by Callahan et al. 2016 (Callahan et al., 2016) to obtain microhaplotypes (S2

246 Fig.). We mapped microhaplotypes obtained from DADA2 against a custom-built database of 3D7 and

247 Dd2 reference sequences for each amplicon locus and filtered microhaplotypes based on edit distance, 
medRxiv preprint doi: https://doi.org/10.1101/2021.09.15.21263521; this version posted September 22, 2021. The copyright holder for this

preprint (which was not certified by peer review) is the author/funder, who has granted medRxiv a license to display the preprint in perpetuity.

It is made available under a CC-BY-NC-ND 4.0 International license .

248 length, and chimeric identification, using a custom R script. (S2 Supporting information). We

249 summarized observed sequence polymorphism into a concise format by converting individual

250 microhaplotypes into pseudo-CIGAR strings using a custom python script. Microhaplotypes were

251 discarded if supported by fewer than 10 read-pairs or by less than $1 \%$ total read-pairs within the locus, or

252 if they exhibited other error features (S3 Supporting information).

253 We analyzed native and pre-amplified mock samples to determine precision and sensitivity of the

254 DADA2 pipeline and filters. We defined a true positive (TP) as a microhaplotype with a pseudo-CIGAR

255 string identical to the reference strain (either 3D7 or Dd2). We defined a false positive (FP) as a

256 microhaplotype with a pseudo-CIGAR string not matching 3D7 (in the case of samples containing only

257 3D7) or not matching 3D7 or Dd2 (in the case of the mixes), and we defined a false negative (FN) as a

258 locus without any correct microhaplotype representation. We defined precision as TP/(TP+FP), and

259 sensitivity (recall) as TP/(TP+FN). Forty-two of 128 P. falciparum loci in AMPLseq exhibit identical 3D7

260 and Dd2 reference sequences; we only included these in precision and sensitivity calculations for pure

261 3D7 controls (i.e., TP+FN = 128); precision and sensitivity calculations for strain mixtures considered

262 only the 86 loci that differ between 3D7 and Dd2 reference sequences (i.e., $T P+F N=86$ ).

263 All amplicon sequencing data were submitted to the NCBI Sequence Read Archive

264 (http://www.ncbi.nlm.nih.gov/sra) under accession PRJNA758191.

\section{Comparator Panels}

266 We compared AMPLseq and 4CAST to two previously published AmpSeq panels for malaria

267 molecular surveillance, Paragon HeOME v1 (Tessema et al., 2020) and SpotMalaria v2 (Jacob et al.,

268 2021).

269 Paragon HeOME v1, designed via CleanPlex algorithm (Paragon Genomics Inc, USA), contains

270100 primer pairs in a single pool. These target 89 P. falciparum loci selected based on high diversity and

271 differentiation (Jost $D \geq 0.21$ ) among clinical isolates from Africa as well as eleven drug

272 resistance-associated loci. A distinctive feature of HeOME library construction involves its requirement 
medRxiv preprint doi: https://doi.org/10.1101/2021.09.15.21263521; this version posted September 22, 2021. The copyright holder for this

preprint (which was not certified by peer review) is the author/funder, who has granted medRxiv a license to display the preprint in perpetuity.

It is made available under a CC-BY-NC-ND 4.0 International license .

273 for bead-based clean-up and CleanPlex digestion of each sample between PCR1 and PCR2. The

274 protocol therefore does not require sWGA prior to PCR1.

275 SpotMalaria v2, designed via Agena BioScience and MPrimer design software, contains 136

276 primer pairs divided into three different pools. These target loci were considered best able to recapitulate

277 pairwise genetic distance, population differentiation, and sample heterozygosity inferences from global

278 WGS data (MalariaGEN Plasmodium falciparum Community Project, 2016). Primers also target various

279 drug resistance-associated loci (some known to exhibit copy number variation) and mitochondrial loci

280 with conserved primer binding sites among Plasmodium spp. Library construction requires sWGA prior to

281 PCR1 but no special processing between PCR1 and PCR2.

282 We also compared our amplicon panels to a 24-SNP molecular barcode assay (Daniels et al.,

283 2008). The SNPs targeted by this Taqman qPCR-based assay were chosen principally for their high

284 minor allele frequency (average MAF > 0.35) in parasite sample collections from Thailand and Senegal

285 (Daniels et al., 2008).

286

\section{paneljudge and in silico data simulations}

We used WGS data to simulate genotypic panel data for simulations. This publication uses data

288 from the MalariaGEN Plasmodium falciparum Community Project as described online pending

289 publication and public release of dataset Pf7 (https://www.malariagen.net/resource/34). Specifically, we

290 used genomic data from monoclonal samples collected in Mali, Malawi, Senegal, and Thailand (Zhu et

291 al., 2019), and from Colombia and Venezuela (ENA accession numbers in S4 Table). We also used

292 previously published monoclonal genomic data from Guyana (SRA BioProject PRJNA543530) (Mathieu

293 et al., 2020) and French Guiana (SRA BioProject PRJNA242182) (Pelleau et al., 2015). We used the

294 scikit-allel library (Miles et al., 2020) to process the data and then estimate microhaplotype frequency

295 and diversity. Specifically, we used the read_vcf, is_het, and haploidify_samples functions as described

296 (S1 Supporting information), and we estimated haplotype frequencies with the distinct_frequencies

297 function.

298 We assessed the performance of different panels for relatedness inference using simulated data.

299 We generated data on pairs of haploid genotypes (equivalent to pairs of monoclonal malaria samples) 
medRxiv preprint doi: https://doi.org/10.1101/2021.09.15.21263521; this version posted September 22, 2021. The copyright holder for this

preprint (which was not certified by peer review) is the author/funder, who has granted medRxiv a license to display the preprint in perpetuity.

It is made available under a CC-BY-NC-ND 4.0 International license .

300 using paneljudge (Taylor \& Jacob, 2020), an R package that we built to simulate data under a hidden

301 Markov model (HMM) (Taylor et al., 2019) (S2 Supporting information). For each panel, we calculated

302 inter-locus distances from the median nucleotide position of each locus and set distances as infinite

303 between chromosomes. For each panel and population of interest, we calculated haplotype frequency

304 estimates using scikit-allel, as described above. Given these distances and frequency estimates, we

305 simulated data using relatedness parameter values of 0.01 (unrelated), 0.50 (siblings), and 0.99 (clonal),

306 and switch rate parameter values of 1, 5, 10, and 50. For each combination of panel, population,

307 relatedness parameter, and switch rate parameter, we simulated data on 100 haploid genotype pairs. For

308 each haploid genotype pair, we then generated estimates of the relatedness parameter and the switch

309 rate parameter using paneljudge, with 95\% confidence intervals (Cls), under the same model used to

310 simulate the data. We next performed relationship classification from these estimates and Cls. For

311 estimates of unrelated pairs (relatedness parameter of 0.01), we generously classified estimates as

312 correct if the lower limit of the $95 \%$ confidence interval $(\mathrm{LCl})$ was below or equal to 0.01 and the upper

313 limit of the $95 \%$ confidence interval (UCI) was below 0.99 . We classified estimates of sibling-level

314 relatedness $(0.50)$ as correct if the $\mathrm{LCl}$ was above 0.01 and the $\mathrm{UCI}$ was below 0.99 . We classified

315 estimates of clonal pairs (0.99) as correct if the LCl was above 0.01 and the UCl was above or equal to

316 0.99. In all relatedness levels, if the $95 \%$ confidence interval spanned both 0.01 and 0.99 (i.e., $\mathrm{LCl}<0.01$

317 and $\mathrm{UCI}>0.99)$, then we denoted the estimate as unclassified.

318 To evaluate panel performance in COI estimation, we combined monoclonal WGS data to

319 engineer in silico polyclonal samples using vcftools (Danecek et al., 2011). We then estimated

320 microhaplotype frequencies for each locus of a given panel, using scikit-allel as described above, and

321 counted the number of distinct microhaplotypes observed at each locus per sample. We estimated COI

322 as the maximum number of distinct microhaplotypes observed at any locus within a sample.

323 To evaluate panel performance for geographic attribution, we identified microhaplotypes at loci as

324 described above. We used the microhaplotype sequences themselves and visualized these data using

325 the Rtsne package (Krijthe, 2015), with 5000 iterations, $\boldsymbol{\Theta}$ of 0.0 , and perplexity parameters of 10 (for

3264 CAST and the 24 SNP barcode) or 30 (for the remaining panels). 
medRxiv preprint doi: https://doi.org/10.1101/2021.09.15.21263521; this version posted September 22, 2021. The copyright holder for this

preprint (which was not certified by peer review) is the author/funder, who has granted medRxiv a license to display the preprint in perpetuity.

It is made available under a CC-BY-NC-ND 4.0 International license.

\section{Results}

\section{4CAST and AMPLseq validation}

We validated assay precision (defined as TP/(TP+FP)), sensitivity (defined as TP/(TP+FN)), and

330 depth of coverage using 3D7 mock clinical samples representing parasitemia levels between 10 and

33110000 parasites/ $\mu \mathrm{l}$ in $10 \mathrm{ng} / \mu \mathrm{l}$ human DNA. Both 4CAST and AMPLseq generated 3D7 microhaplotype

332 calls with $100 \%$ precision for all parasitemia levels assessed, both with and without pre-amplification by

333 sWGA. 4CAST achieved high sensitivity and depth without preliminary sWGA, generating a median of 43

334 read-pairs per locus from native templates representing 10 parasites/ $\mu$ l (Fig. 3A). Median depth

335 increased to 443 and 1312.5 read-pairs per locus for native templates representing 100 and 1000

336 parasites/ $\mu \mathrm{l}$, respectively. Read-pair counts were also evenly distributed among 4CAST loci using native

337 DNA (Fig. 3A).

338 Unlike 4CAST, AMPLseq required sWGA for 3D7 mock samples representing $\leq 100$ parasites/ $\mu$ l

339 (Fig. 3B). Following sWGA on mock samples representing 10 parasites/ $\mu \mathrm{l}$, the assay generated $\geq 10$

340 read-pairs at a median of 126 loci, with a median of 465 read-pairs after excluding loci with fewer than 10

341 reads. Values were statistically similar for pre-amplified samples representing 100 parasites $/ \mu$ l and

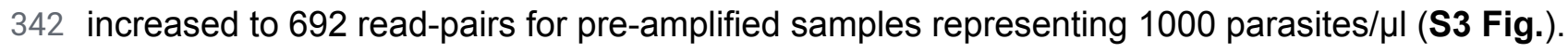

343 We also validated the sensitivity of 4CAST and AMPLseq for genotyping polyclonal infections by

344 using mock samples containing both 3D7 and Dd2 templates (likewise in $10 \mathrm{ng} / \mu \mathrm{l}$ human DNA). These

345 mixtures featured Dd2 at 50\% (i.e., 1:1 3D7:Dd2 ratio), 25\% (3:1), and 9\% (10:1) relative abundance.

346 Total parasitemia levels ranged between 10 and 10000 parasites/ $\mu$ l. Both 4CAST and AMPLseq

347 generated microhaplotype calls with $100 \%$ precision at the 86 loci that are dimorphic between the 3D7

348 and Dd2 references (including all four 4CAST loci and an additional 82 loci in AMPLseq). This perfect

349 precision was observed at all parasitemia levels in both native and pre-amplified mock mixtures of the

350 two strains.

351 4CAST showed high sensitivity for Dd2 without the need for sWGA. At 1000 parasites/ $\mu$, the

352 assay detected Dd2-specific microhaplotypes at each of its four loci in all 1:1, 3:1, and 10:1 mixture

353 replicates (Fig. 3C). At 100 parasites/ $\mu$ l, median Dd2 sensitivity remained $100 \%$ at $1: 1$ and $3: 1$ ratios but 
medRxiv preprint doi: https://doi.org/10.1101/2021.09.15.21263521; this version posted September 22, 2021. The copyright holder for this

preprint (which was not certified by peer review) is the author/funder, who has granted medRxiv a license to display the preprint in perpetuity.

It is made available under a CC-BY-NC-ND 4.0 International license .

354 lowered slightly to $94 \%$ at $10: 1$. Sensitivity for each strain decreased at 10 parasites/ $\mu$, with $1: 1$ ratios

355 yielding a median of 3 target loci for 3D7 and a median of 2 targets for Dd2; median sensitivity in these

356 samples rose to 3.5 and 3 loci (respectively) following pre-amplification with sWGA, but this led to

357 unbalanced read-pair support between the two strains (S4A Fig.), possibly due to differential sWGA

358 success on low-quality Dd2 vs. high-quality 3D7 templates. 4CAST read-pair ratios generated from

359 native templates, by contrast, showed a very high correlation with input ratios at $100 \mathrm{p} / \mu \mathrm{l}$ (S4A Fig.) and

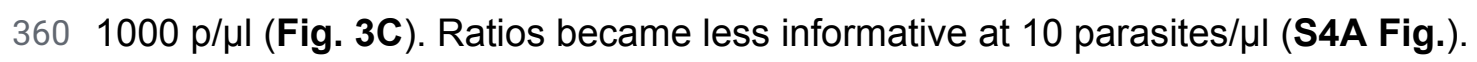

361 AMPLseq (with sWGA) was also successful in detecting Dd2-specific microhaplotypes, but only

362 at a maximum of 77 of 86 dimorphic loci (in the 1:1 ratio at 10000 parasites $/ \mu l$ ). Dd2-specific sequences

363 were detected at a minimum of two dimorphic loci for all three input ratios $(1: 1,3: 1,10: 1)$ and

364 parasitemia levels ( $\geq 10 \mathrm{p} / \mu \mathrm{l}$ ) assessed. Like with 4CAST, however, the use of sWGA decorrelated

365 read-pair ratios from input ratios (S4B Fig.). Dd2 sensitivity was also reduced relative to 3D7 sensitivity

366 (median Dd2 sensitivity / 3D7 sensitivity $=58 \%$ ) with sWGA. These discrepancies were not observed

367 with native templates (Fig. 3D) at $\geq 1000$ parasites/ $\mu$ l for which AMPLseq achieves high read-pair support

368 without the use of sWGA.

369 We also tested both panels on genomic DNA extracted from dried blood spots collected by the

370 Guyana Ministry of Health in 2020 from individuals diagnosed as $P$. falciparum-positive via a rapid

371 diagnostic test (RDT). Ten Guyanese samples were tested with both panels, and an additional six were

372 tested with AMPLseq. Using 4CAST, we observed coverage across all loci in all samples, with a median

373 read-pair depth per locus of 1162 read-pairs without sWGA (Fig. 3A). Using AMPLseq (with sWGA), we

374 observed a median of 122 loci with $\geq 10$ read-pairs and a median read-pair depth of 298 read-pairs per

375 covered locus (Fig. 3B).

376 Additionally, we tested both panels on gDNA extracted from 16 dried blood spot samples

377 collected in Mali in 2011 (Tran et al., 2013) and subsequently stored at room temperature for ten years.

378 Using 4CAST (without sWGA), we observed a median read-depth of 407 read-pairs per locus (Fig. 3A).

379 Using AMPLseq (with sWGA), we observed a median of 75 loci with $\geq 10$ read-pairs and a median

380 read-depth of 112 read-pairs per covered locus (Fig. 3B). 

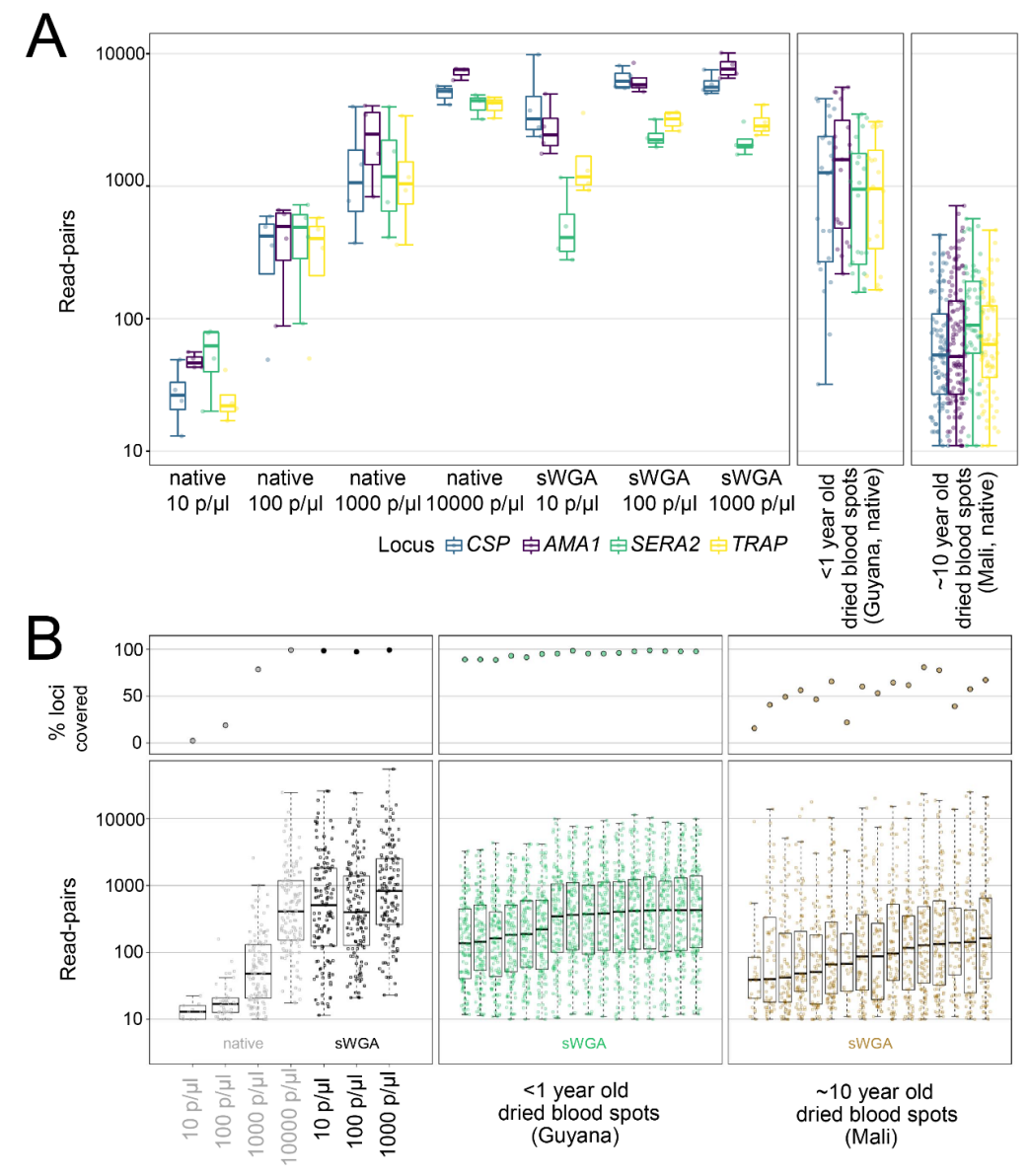

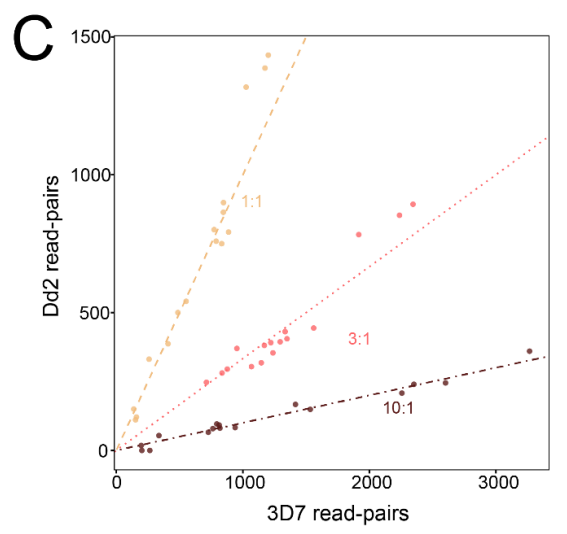

D

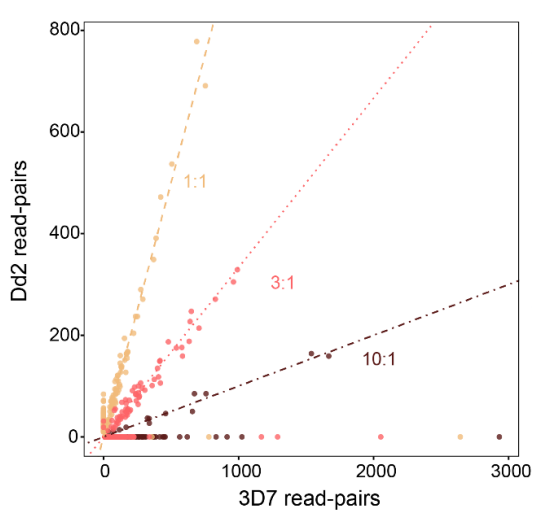

381 Figure 3. 4CAST and AMPLseq panel validation with mock and clinical samples.

382 A) Boxplots of read-pairs per locus in the 4CAST panel. The first facet shows read-depth per locus 383 across mock samples ranging from 10 - $10000 \mathrm{p} / \mu \mathrm{l}$, both native DNA and sWGA DNA ( $\mathrm{n}=4$ per condition). The second and third facets show read-depth per locus across two sets of clinical samples,

$385<1$ year old and $\sim 10$ year old dried blood spots, respectively ( $n=32$ per sample set). B) The same 3D7 386 mock sample sets were used to assess AMPLseq sensitivity (top left panel of B) and sequencing depth 387 (bottom left panel of B). Each point in the bottom left panel of B represents read-pair support for one 388 AMPLseq locus. Positions on the $y$-axis indicate median read-pair support across replicate samples. Low

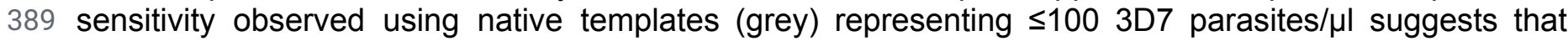
390 clinical samples should be pre-amplified with sWGA (results at right). C) Ratio of read-pairs from 391 microhaplotypes assigned to 3D7 (x-axis) or Dd2 (y-axis) from mock mixtures of these DNAs in ratios of 392 1:1 (tan), 3:1 (pink), and 10:1 (dark red). All samples contained 1000 parasites per $\mu$ l total, across both 393 DNA sources. Dashed lines represent the expected ratio, and each point represents a 4CAST locus per 394 sample ( $n=4$ per condition). D) AMPLseq read-pair ratios observed in native 3D7+Dd2 mock mixtures 395 (1000 parasites/ $\mu$ l) are plotted as above (C) for 4CAST.

\section{Evaluation of panel performance for relatedness}

We used the R package paneljudge to assess in silico the impact of choosing a specific

398 genotyping panel for relatedness inference. Considering the choice of panel, we evaluated relatedness 
medRxiv preprint doi: https://doi.org/10.1101/2021.09.15.21263521; this version posted September 22, 2021. The copyright holder for this preprint (which was not certified by peer review) is the author/funder, who has granted medRxiv a license to display the preprint in perpetuity.

It is made available under a CC-BY-NC-ND 4.0 International license .

399 estimation from data simulated on our 4CAST and AMPLseq panels, the SpotMalaria v2 (Jacob et al.,

400 2021) and Paragon HeOME v1 (Tessema et al., 2020) amplicon panels, and a barcode of 24 SNPs.

401 When data were simulated using microhaplotype frequency estimates of Senegalese parasites, we found

402 that almost all estimates of unrelated or clonal pairs were correctly classified, regardless of the panel

403 (Fig. 4A). All three large panels also performed similarly well in accurately identifying partially-related

404 parasite pairs, despite being the product of three distinct design processes. Neither 4CAST nor the 24

405 SNP barcode estimated relatedness for partially-related samples as well as the larger panels. We also

406 evaluated panel performance in less diverse parasite populations (Colombia and Thailand), including a

407 population not used in the panel designs (Colombia). We repeated the simulations using microhaplotype

408 frequencies estimated with these data. Again, we found that all panels performed well for estimating

409 relatedness of clonal pairs, and that the 24 SNP barcode and 4CAST were less likely to have correctly

410 classified estimates of non-clonal pairs. With the data simulated using Colombian microhaplotype

411 frequencies from the Pacific Coast region, all three large panels performed well for all three relatedness

412 values, despite the Colombian data not having informed the design of any of the panels.

413 Pairwise relatedness estimates (Schaffner et al., 2018) from AMPLseq correlated highly with

414 those from WGS data available for the Guyanese sample set (Pearson's $r=0.86$, slope $=1.01, p<$

415 0.001) (Fig. 4B). Despite patient travel history metadata suggesting infections to have occurred in

416 various geographic regions of Guyana (S1 Table), AMPLseq relatedness estimates for the Guyanese

417 sample set are significantly higher than those for the Malian sample set (Mann Whitney $U, p<0.001$ ),

418 consistent with anticipated lower transmission levels in Guyana. Nevertheless, the wide range of

419 relatedness estimates $(0.007$ - 1) observed among Guyanese sample comparisons suggests AMPLseq

420 capacity to indicate epidemiologically relevant microstructure even in relatively unstructured parasite

421 populations. For example, the first (lowest) quartile of pairwise relatedness estimates from Guyana was

422 enriched for comparisons involving A2-GUY and C5-GUY, two highly related samples that in whole

423 genome analysis show 50\% relatedness with a sample from Venezuela (SPT26229, see S4 Table). 

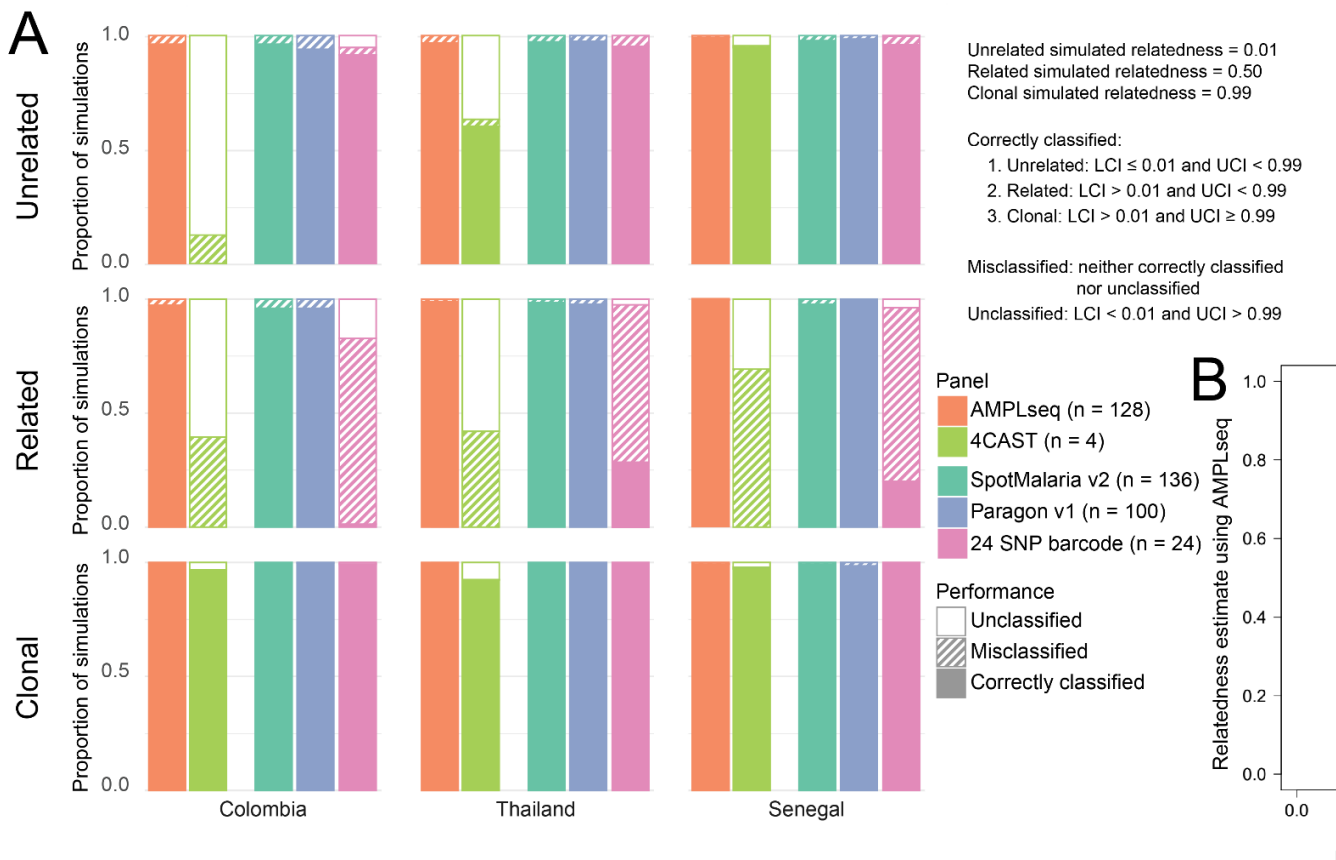

Unclassified: $\mathrm{LCl}<0.01$ and $\mathrm{UCl}>0.99$
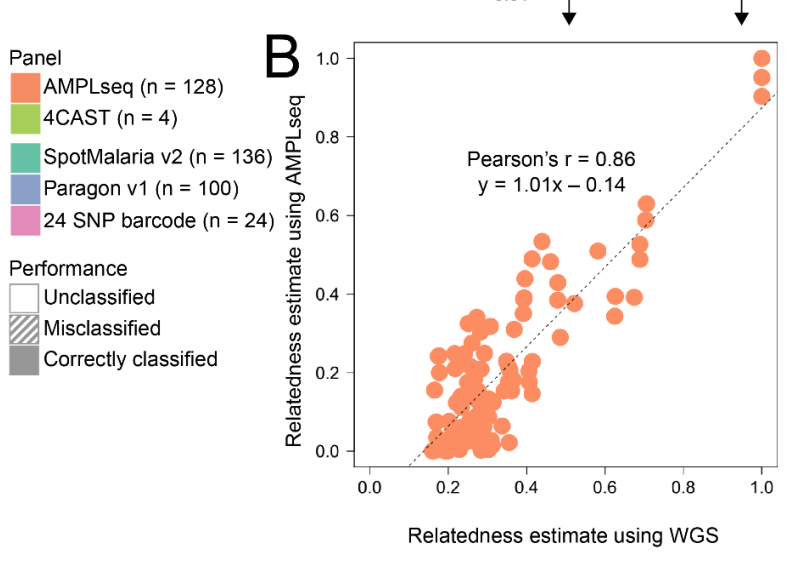

424 Figure 4. In silico relatedness estimation comparisons among panels and empirical AMPLseq 425 validation against WGS.

426 A) Evaluation of relatedness estimation from data simulated on genotyping panels using the paneljudge $427 \mathrm{R}$ package. Pairs of haploid genotypes were simulated at each locus of a panel, using microhaplotype 428 frequencies estimated from a given parasite population (Colombia, Thailand, or Senegal, as shown in 429 columns from left to right). Genotype pairs were simulated at three levels of relatedness: unrelated 430 (relatedness $=0.01$ ), related (relatedness $=0.50$ ), and clonal (relatedness $=0.99$ ), as shown in the rows 431 from top to bottom. Relatedness estimates of these pairs were classified using their $95 \%$ confidence 432 intervals ( $\mathrm{LCl}=$ lower limit of the $95 \%$ confidence interval, $\mathrm{UCI}=$ upper limit of the $95 \%$ confidence 433 interval). Estimates could be correctly classified, misclassified, or unclassified, as described in the grey 434 box. Each bar represents the proportion of simulations per condition $(n=400)$ classified in each 435 category. Bars that are filled with a color represent correctly classified simulations, bars that are hashed 436 represent misclassified simulations, and bars that are filled with white represent simulations that were 437 unable to be classified. The colors of the bars represent the panel used in that set of simulations. B) 438 Empirical AMPLseq results recapitulate WGS-based relatedness inference. Points represent relatedness 439 estimates (hmmIBD (Schaffner et al., 2018) 'fract_sites_IBD' computed under default settings) for pairs 440 of Guyanese samples using WGS ( $n=9408$ variants) vs. AMPLseq ( $n=220$ variants, from within 128 441 AMPLseq P. falciparum loci).

\section{Geographic attribution}

We again engineered amplicon data in silico to evaluate the relative signal in genotyping panels

444 for geographic attribution of samples (Fig. 5). By sub-sampling WGS variant calls, calling

445 microhaplotypes, and visualizing these data using t-SNE plots, we found that results from both the 24

446 SNP barcode (Daniels et al., 2008) and 4CAST distinguished samples by continent of origin, though not

447 by country. Results from all three larger panels additionally distinguished non-African samples by 
medRxiv preprint doi: https://doi.org/10.1101/2021.09.15.21263521; this version posted September 22, 2021. The copyright holder for this preprint (which was not certified by peer review) is the author/funder, who has granted medRxiv a license to display the preprint in perpetuity.

It is made available under a CC-BY-NC-ND 4.0 International license .

448 country, and these panels separated East African (Malawi) from West African samples (Mali/Senegal) to

449 varying degrees; no panel was able to distinguish between Malian and Senegalese samples in this

450 visualization. We also added empirical AMPLseq data from 5 Guyanese samples (C3-GUY, C4-GUY,

451 C5-GUY, C7-GUY, and C8-GUY) and WGS data sub-sampled to AMPLseq coordinates for Venezuelan

452 sample SPT26229 (S5 Fig.). The AMPLseq samples formed a small cluster beside the WGS-based

453 Guyanese and French Guianese samples. The Venezuelan sample SPT26229 also placed on the

454 perimeter of the Guyana/French Guiana sample cluster, sharing the same axis-2 position as the

455 empirical AMPLseq points. Results show that empirical AMPLseq data can distinguish autochthonous

456 samples from the Guiana shield, and we expect geographic attribution in the region to improve as more

457 data are collected from infections originating in Venezuela and other undersampled localities.
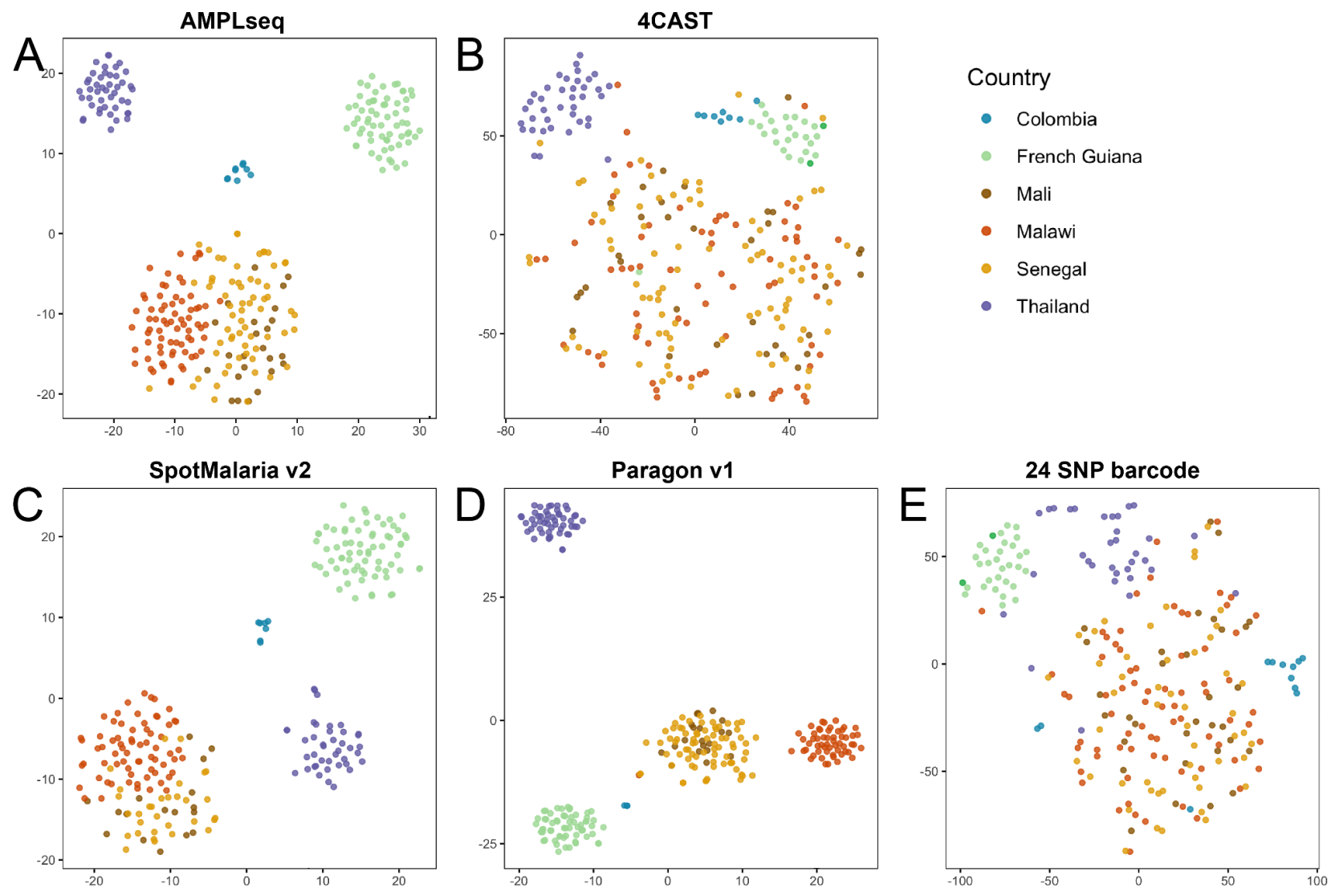

458 Figure 5. In silico geographic attribution comparison among panels.

459 Visualization of WGS data subset to coordinates of genotyping panels. Microhaplotypes called at each

460 locus were visualized using tSNE through the Rtsne package, with parameter $\Theta$ of $0.0,5000$ iterations,

461 and a perplexity parameter of 30 (A, C, D) or 10 (B, E). Each dot represents a single sample, colored by

462 its country of origin (which was not included in the tSNE algorithm). One genotyping panel is visualized in

463 each plot: (A) AMPLseq, (B) 4CAST, (C) SpotMalaria v2, (D) Paragon v1, (E) 24 SNP barcode. 
medRxiv preprint doi: https://doi.org/10.1101/2021.09.15.21263521; this version posted September 22, 2021. The copyright holder for this

preprint (which was not certified by peer review) is the author/funder, who has granted medRxiv a license to display the preprint in perpetuity.

It is made available under a CC-BY-NC-ND 4.0 International license .

464

465

466

467

468

469

470

471

472

473

474

475

476

477

478 for the sample. WGS sequencing coverage, by contrast, detected only moderately elevated SNP

479 heterozygosity (1.9\%) in C6-GUY and this elevation was not sufficient to classify COI>1 via The Real

480 McCoil (Chang et al., 2017) (S7 Fig.). AMPLseq also identified COI=2 for C6-GUY but without consistent

481 support between replicates ( 2 vs. 6 biallelic loci). Six additional Guyanese samples were assayed by

482 AMPLseq and one was classified as COI=2. This sample (A5-GUY) gave a stronger minor variant signal

483 in both AMPLseq (15 biallelic loci in both replicates) and WGS data (10.9\% SNP heterozygosity) (S7

484 Fig.).

485

For the Malian sample set, 4CAST and AMPLseq both classified samples E5-PST030 and

486 C6-PST063 as monoclonal and all other samples as polyclonal based on presence/absence of

487 multiallelic loci. While 4CAST detected as many as 10 alternate alleles (median $=3$ ) per sample locus

488 (Fig. 6B), AMPLseq detected at most 4 (median = 2). These results reaffirm 4CAST as a tool of choice

489 for resolving higher COI levels and when parasitemia levels are low. AMPLseq may reach simulated 
490 performance levels (S6 Fig.) by reducing sample multiplexing or sequencing on higher output platforms

491 (e.g., NovaSeq) for sample sets with low parasitemia.
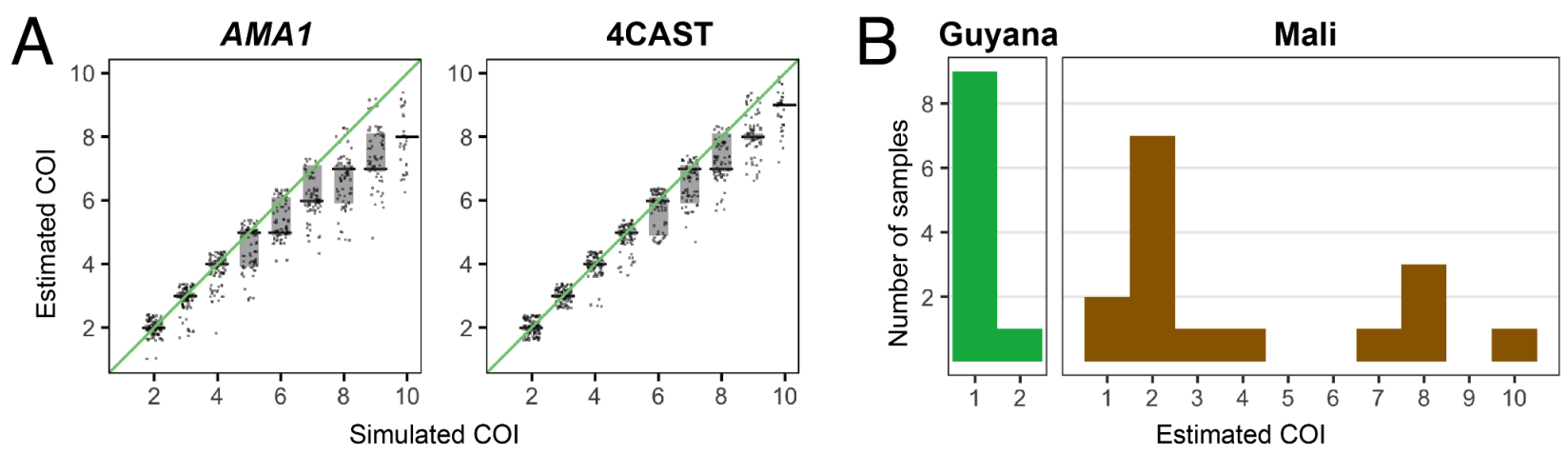

492 Figure 6. In silico and empirical complexity of infection (COI) inference.

493 A) Scatter plots of estimated COI for samples simulated from combinations of monoclonal WGS data, 494 subsetted to the loci of interest (AMA1 locus or 4CAST loci). The $\mathrm{x}$-axis represents the number of

495 monoclonal genomes combined into each simulation, and the $y$-axis represents the COI estimated using

496 the simulated data. COI was naively estimated as the maximum number of unique microhaplotypes

497 present at any locus per sample ( $n=100$ samples per condition). Each dot represents a sample, jittered

498 for visibility. The black bars represent the median and light grey boxes represent the 25th -75 th

499 quantiles. B) Estimated COI for clinical samples sequenced using 4CAST. COI was again estimated as

500 the maximum number of unique microhaplotypes present at any locus in the sample.

501 Longitudinal sampling: distinguishing recrudescence vs. reinfection

We used 4CAST to examine longitudinal samples that were likely to be diverse and polyclonal.

503 We sequenced samples from the same asymptomatic individual in the longitudinal Mali cohort over three

504 consecutive visits (Fig. 7) (Tran et al., 2013). We detected a single microhaplotype at each locus that

505 was present in the first two time points, suggesting a continued infection during the two weeks between

506 samples. At the third time point, we detected a single, distinct microhaplotype at each locus, suggesting

507 that a new infection had occurred and the original infection had disappeared or decreased below our limit

508 of detection $(<10 \mathrm{p} / \mu \mathrm{l})$. In this particular case, the individual was asymptomatic and did not receive

509 anti-malarial treatment between any samples; however, this simple example demonstrates the clarity that

510 4CAST can bring to tracking infection turnover in longitudinal studies, and suggests its utility in

511 distinguishing recrudescence vs. reinfection in therapeutic efficacy studies. 


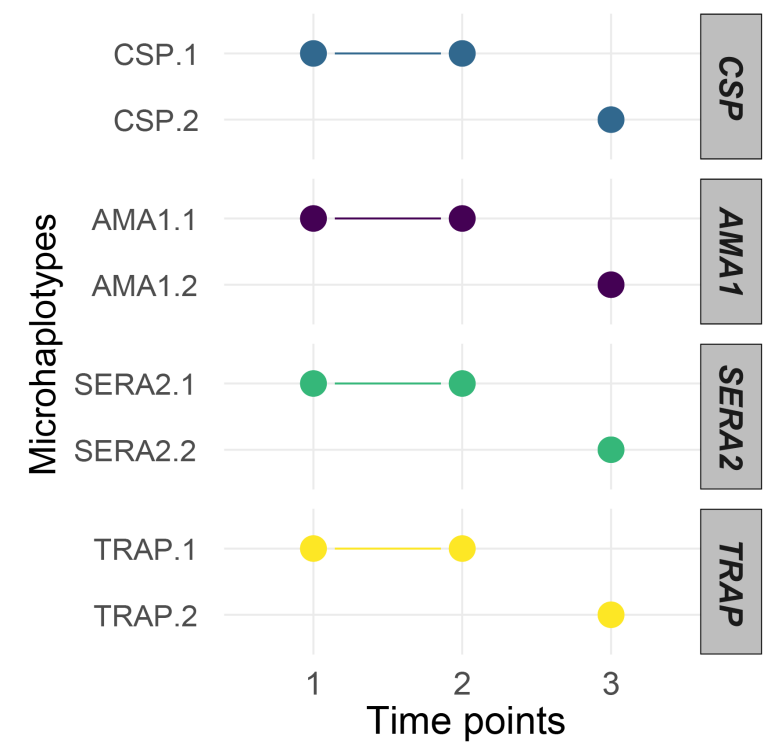

512 Figure 7. Longitudinal tracking of infections using 4CAST.

513 Identification of distinct microhaplotypes present in samples from an individual at three consecutive time

514 points. The $x$-axis represents the three time points, and the $y$-axis represents the individual

515 microhaplotypes identified, grouped by locus. Dots represent the presence of that microhaplotype,

516 connected when present in consecutive visits.

\section{Drug resistance profiling}

AMPLseq loci in $d h f r, m d r 1, d h p s, k e l c h 13$, and $m d r 2$ contain ten sequence regions that code for

519 various amino acid (AA) polymorphisms that have previously been associated with resistance to

520 antimalarial drugs (Ariey et al., 2014; Miotto et al., 2015; Mita et al., 2007; Veiga et al., 2016)Thirteen of

521 these 18 positions of interest contained nonsynonymous mutations in Malian and Guyanese clinical

522 samples of this study (Fig. 8). Positions of interest that lacked mutations across both sample sets were

523 DHFR AA 59 and 164; DHPS AA 613; KELCH13 AA 580; and MDR2 AA 484. All Guyanese sequences

524 shared the same mutant alleles at many loci. Malian samples, by contrast, did not show fixed mutant

525 alleles at any amino acid position of interest. A mix of mutant and wildtype alleles occurred among

526 Malian samples for DHFR AA 51 and 108; MDR1 AA 86, 184, and 1246; DHPS AA 436 and 437; and

527 MDR2 AA 492. A previously reported synonymous polymorphism was observed in one Malian sample at

528 KELCH13 AA 589 (Taylor et al., 2015). 

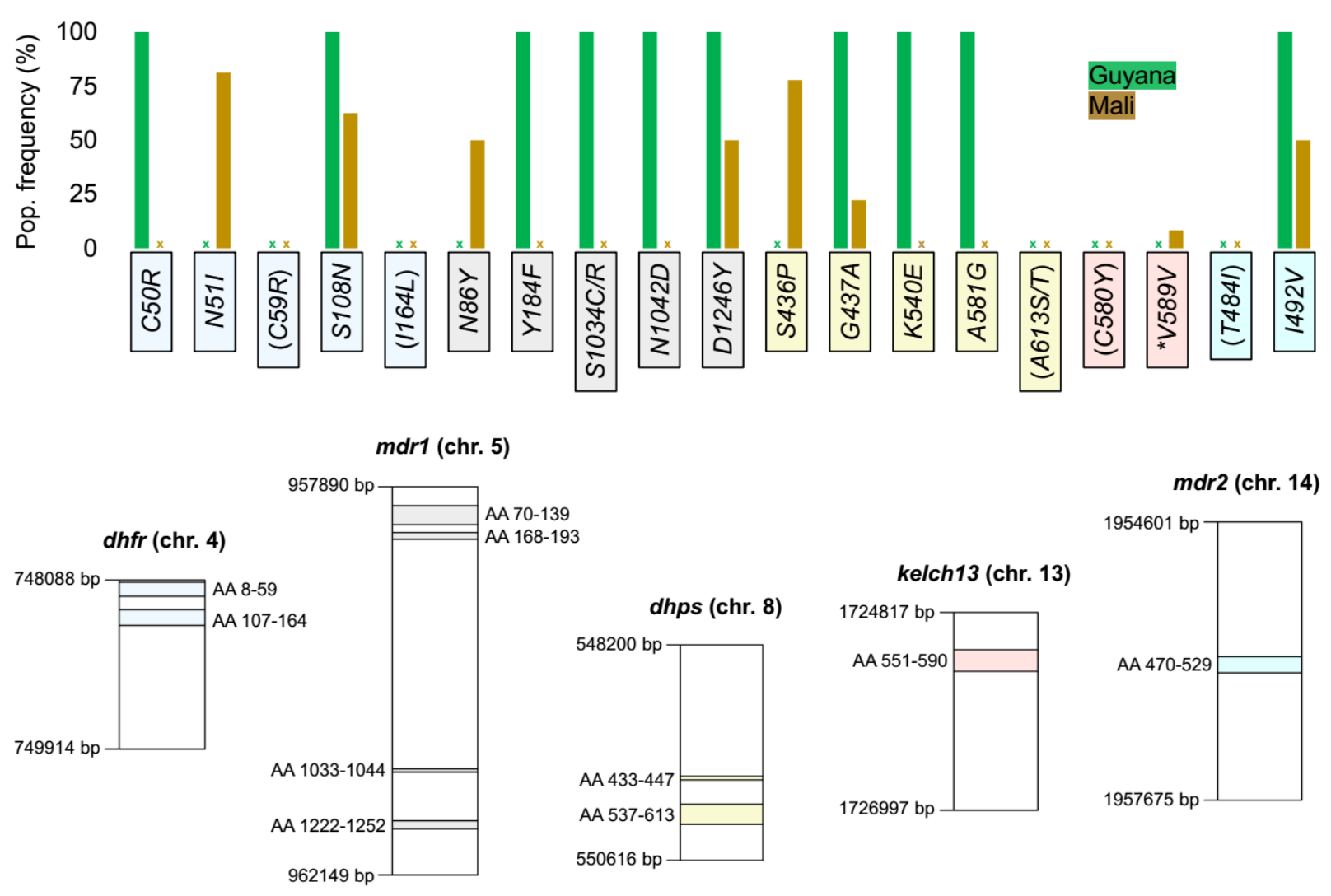

\section{Figure 8. Drug resistance-associated sequence profiling in Guyanese and Malian clinical \\ 530 samples.}

531 Bars in the top plot indicate the occurrence of various drug resistance-associated amino acid changes

532 within AMPLseq loci. Positions of interest assayed by AMPLseq but without mutant alleles (see x-marks)

533 in the clinical samples profiled here are labeled in parentheses. Positions 484 and 492 in mdr2 have

534 been suggested to be involved in artemisinin resistance despite lack of experimental data showing an

535 association with a clinical phenotype (Chenet et al., 2017; Miotto et al., 2015). Bottom plot indicates

536 chromosomal and amino acid (AA) positions of each drug resistance-associated AMPLseq locus.

537 Asterisk indicates synonymous mutation within kelch13.

\section{P. falciparum and $P$. vivax co-infection detection}

539 To test the ability of AMPLseq to detect $P$. vivax co-infections via co-amplification of $P v D H F R$, two

540 additional Guyanese blood spot samples that had been diagnosed as $P$. vivax-only (G4G430) and $P$.

541 vivax + P. falciparum co-infection (G4G180) via RDT were included in the sample set. These samples did

542 not undergo sWGA.

543 PVDHFR was detected at high depth in both samples (1068 - 1822 read-pairs for G4G430 and

544234 - 560 read-pairs for G4G180) (Fig. 9). Only G4G180 also showed read-pair support at $P$. falciparum

545 panel loci (>10 read-pairs at $100-115$ loci). PVDHFR was not detected in any native or pre-amplified

546 3D7 or mixed-strain (3D7 + Dd2) templates. This demonstrates high specificity of both PvDHFR and $P$. 
medRxiv preprint doi: https://doi.org/10.1101/2021.09.15.21263521; this version posted September 22, 2021. The copyright holder for this preprint (which was not certified by peer review) is the author/funder, who has granted medRxiv a license to display the preprint in perpetuity.

It is made available under a CC-BY-NC-ND 4.0 International license .

547 falciparum AMPLseq primers to their intended target species without any apparent amplification inhibition

548 by the presence of congeneric DNA.

549 PVDHFR was also detected at low levels (16 - 30 read-pairs) in both native template replicates of

550 C7-GUY, one of the sixteen Guyanese samples previously diagnosed as $P$. falciparum-only via RDT.

551 Surprisingly, two PVDHFR read-pairs were also detected in one of the two sWGA replicates from the

552 sample, despite the expectation that sWGA would primarily amplify $P$. falciparum sequencines.

553 Sensitivity of PvDHFR detection in pre-amplified samples could be enhanced by adding PvDHFR primers

554 to the P. falciparum sWGA primer pool. PVDHFR detection did not occur in any Malian sample,

555 consistent with low prevalence of $P$. vivax in West Africa relative to the Guiana shield.
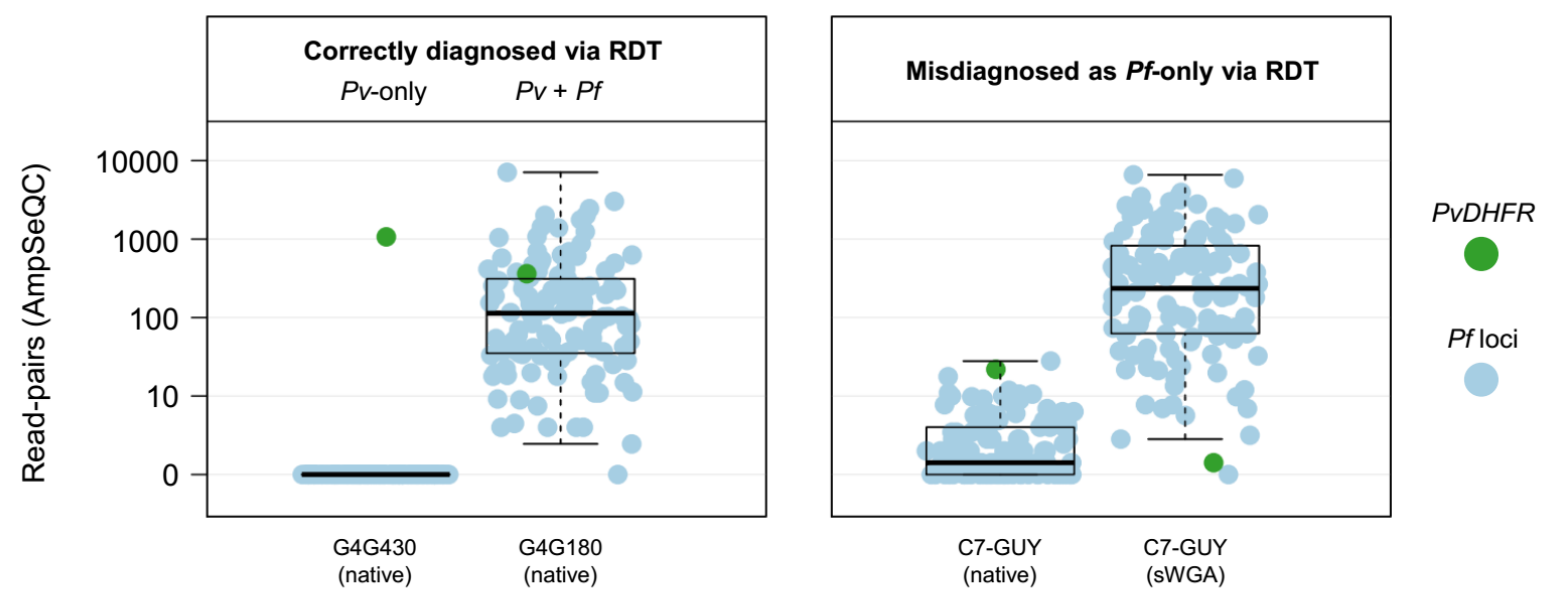

\section{Figure 9. Plasmodium vivax detection by AMPLseq.}

557 The left panel demonstrates strong read support for $P V D H F R$ (green circle) in native control samples

558 previously suggested to contain $P$. vivax (Pv; G4G430) and P. vivax + P. falciparum (Pv + Pf; G4G180)

559 via RDT. The right panel shows native and sWGA results for C7-GUY, a clinical sample that appears to

560 have been misdiagnosed as $P f$-only prior to AMPLseq. Blue circles represent read support for $P$.

561 falciparum loci. Positions on the y-axis indicate median read-pair support across two sample replicates.

562 Box and whiskers indicate quartiles.

\section{Discussion}

564 The utility of AmpSeq for molecular surveillance of infectious diseases is evidenced by the

565 growing number of protocols recently published or under development for Plasmodium and other

566 pathogens (Aydemir et al., 2018; Fola et al., 2020; Jacob et al., 2021; Mitchell et al., 2021; Moser et al.,

567 2021; Ruybal-Pesántez et al., 2021; Schwabl et al., 2020; Tessema et al., 2020). Here, we demonstrate 
medRxiv preprint doi: https://doi.org/10.1101/2021.09.15.21263521; this version posted September 22, 2021. The copyright holder for this

preprint (which was not certified by peer review) is the author/funder, who has granted medRxiv a license to display the preprint in perpetuity.

It is made available under a CC-BY-NC-ND 4.0 International license .

568 the performance of two new panels for $P$. falciparum, designed to serve different use cases and

569 exhibiting different per-sample costs and levels of complexity. Our comparative analyses of these two

570 new panels, AMPLseq and 4CAST, relative to previously published genotyping panels demonstrates that

571 they perform comparably to existing panels of similar composition across use cases, in a diversity of

572 geographic settings, despite different geographic representation in the population genomic data used to

573 inform their designs. This suggests that de novo custom panel design may not be required for accurate

$574 \mathrm{COI}$ and relatedness estimation in parasite populations from previously unstudied geographic regions.

575 We therefore suggest that future implementation of these panels should be guided by three criteria: 1)

576 the intended use cases for the data, 2) protocol complexity and compatibility with available instruments

577 and expertise, and 3) protocol customizability for locally relevant genetic loci.

578 Considering the first of these criteria, intended use case, our investigations above suggest a

579 straightforward mapping of panels by size and feature to use case. The small 4CAST panel is well suited

580 to COI estimation (Fig. 6), and profiles four highly diverse antigens for the same effort and cost

581 traditionally used to profile a single locus. Because of the very high diversity of the loci in the 4CAST

582 panel in most parasite populations, this panel is also well suited to any application requiring genetic

583 delineation of distinct parasite lineages (Fig. 7). In therapeutic efficacy studies, for example, it is

584 essential to determine whether subjects who become parasitemic following drug treatment are exhibiting

585 a recrudescence of an incompletely-cleared strain from the initial infection (which could indicate

586 treatment failure), or if they have become reinfected with a distinct parasite strain subsequent to

587 treatment. We suggest that the 4CAST panel would be significantly more informative than traditional

588 genotyping approaches used in therapeutic efficacy studies, such as profiling length polymorphisms or

589 allele-specific amplification in the MSP1/MSP2/GLURP loci (Reeder \& Marshall, 1994; Snounou, 2002),

590 and more cost-effective than independent monoplex amplification and Illumina sequencing of individual

591 loci (Early et al., 2019; Gruenberg et al., 2019; Lerch et al., 2017).

592 Our work also demonstrates that the AMPLseq panel performs comparably to two existing

593 multiplexed amplicon sequencing panels of similar size (Jacob et al., 2021; Tessema et al., 2020) for any

594 use case reliant on estimation of parasite relatedness (Fig. 4), despite different design criteria and 
medRxiv preprint doi: https://doi.org/10.1101/2021.09.15.21263521; this version posted September 22, 2021. The copyright holder for this

preprint (which was not certified by peer review) is the author/funder, who has granted medRxiv a license to display the preprint in perpetuity.

It is made available under a CC-BY-NC-ND 4.0 International license .

595 datasets that informed the panels. Potential public health use cases that employ relatedness information

596 include measuring the connectivity of parasites between locations to define units of control, and

597 monitoring changes in the level of transmission (Cerqueira et al., 2017; Daniels et al., 2015; Knudson et

598 al., 2020). The AMPLseq panel and its peers are also much better suited to detecting imported infections

599 given their improved capacity to distinguish parasites from distinct geographic locations (Fig. 5.) Finally,

600 the larger panels offer the capacity to monitor genetic markers associated with drug resistance (Fig. 8)

601 or, in some panels, detect co-infection with other Plasmodium species (Fig. 9).

602 The second panel selection criterion, protocol complexity and compatibility with available

603 instruments, should be prefaced with a reminder that all of these protocols employ nested PCR reactions

604 as the fundamental mechanism to produce sequencing libraries targeting small genomic regions of

605 interest. Any molecular laboratory with a capacity for PCR and a small sequencing instrument such as an

606 Illumina iSeq100 will be capable of carrying out any of these protocols. The exquisite sensitivity of

607 amplicon sequencing implemented via an Illumina platform means that all of these protocols are also

608 susceptible to contamination. PCR reactions should be conducted in dedicated hoods, ideally in rooms or

609 locations physically removed from settings in which PCR products are manipulated. Finally, all of these

610 protocols share: 1) a requirement for careful cleanup of inappropriately large or small DNA molecules

611 from pooled libraries prior to sequencing, 2) precise quantification of said libraries for optimal loading on

612 the sequencing instrument, and 3) large batch sizes (samples in increments of 96, 192, or larger to

613 accommodate the capacity of the intended sequencing instrument).

614 Though these AmpSeq protocols share many common features, they differ in other aspects that

615 may impact implementation. Whereas the 4CAST and Paragon panels and single nested PCR reactions

616 perform well on native DNA from clinical samples, the AMPLseq and SpotMalaria panels require sWGA

617 pre-amplification prior to the first PCR reaction to ensure adequate performance for samples with

618 parasitemia at or below 100 parasites/ $\mu \mathrm{l}$, which may comprise a significant proportion of samples in

619 some settings. sWGA is an isothermal amplification protocol that is relatively simple to perform but

620 requires an expensive phi29 DNA polymerase and a magnetic bead-based cleanup of individual samples

621 afterward, for an approximate additional cost of \$8 USD per sample at the time of writing. Though not 
medRxiv preprint doi: https://doi.org/10.1101/2021.09.15.21263521; this version posted September 22, 2021. The copyright holder for this

preprint (which was not certified by peer review) is the author/funder, who has granted medRxiv a license to display the preprint in perpetuity.

It is made available under a CC-BY-NC-ND 4.0 International license .

622 large in absolute terms, this cost is comparable to the cost of the AMPLseq or 4CAST protocols

623 themselves, which range from \$5 - 10 USD per sample, depending on details of implementation such as

624 sequencing instrument and sample indexing per run. The larger panels additionally employ differing

625 numbers of first-round PCR reactions and require a varying number of magnetic bead-based cleanups to

626 tailor the length profile of intermediate products (summarized in S5 Table), which means that the local

627 capacity for automating the bead-based cleanups is a relevant implementation consideration.

628 The third criterion for panel selection, customizability, may be most relevant for the drug

629 resistance surveillance use case, given differences in the geographic distribution of important drug

630 markers, and varying coverage of known markers by the existing panels. All of the protocols are

631 amenable to customization through the addition of independent target amplifications in the first round of

632 PCR, which could be combined with other first-round PCR multiplex products prior to the second PCR. A

633 more elegant customization approach would be to add (or subtract) targets from the first-round PCR

634 reaction. While complicated bioinformatic pipelines are useful or essential in the design of large

635 multiplexes, in our experience, small multiplexes like 4CAST, which was made from pre-existing primer

636 pairs designed independently, may simply function without optimization, and could presumably be

637 augmented with a small number of additional loci. Though the AMPLseq multiplex of 129 PCR loci

638 benefited from careful design of the original panel, we added the 4CAST targets to the designed

639 AMPLseq target set with no primer modifications and found it to be functional, suggesting it is likely

640 receptive to further augmentation. As the AMPLseq and 4CAST protocols utilize unmodified,

641 commercially available oligos as primers, further customization should be feasible in any setting.

642 However, we must note that not all targets are amenable to incorporation into the multiplex, as we failed

643 despite multiple attempts to include amplicons targeting the pfcrt gene associated with chloroquine

644 resistance (Fidock et al., 2000), or the $h r p 2 / 3$ genes, which can contain deletions that lead to

645 false-negative diagnosis via rapid diagnostic test (Gamboa et al., 2010).

646 The proliferation of new AmpSeq protocols for molecular surveillance of infectious diseases

647 raises the important question of whether it is valuable for each disease field to converge on a single

648 approach or common panel. Factors precluding a completely homogeneous approach include varying 
medRxiv preprint doi: https://doi.org/10.1101/2021.09.15.21263521; this version posted September 22, 2021. The copyright holder for this

preprint (which was not certified by peer review) is the author/funder, who has granted medRxiv a license to display the preprint in perpetuity.

It is made available under a CC-BY-NC-ND 4.0 International license .

649 instrumentation, expertise, and use cases for the data across settings, in addition to an anticipated

650 onward evolution of genotyping technology and elucidation of new markers of interest for drug resistance

651 or other phenotypes. Factors favoring convergence include opportunities for improved procurement of

652 instruments and reagents at a regional level in malaria-endemic countries, and opportunities to directly

653 compare observations between studies and surveillance efforts led by different groups. This latter factor,

654 which we term portability of analyses, has the potential to provide regional or global insight through

655 syntheses across studies. However, the portability of certain analyses is hampered by ascertainment

656 bias, an inherent limitation of any targeted sequencing approach for analyses based on the genotypic

657 state of select loci in different countries. That is, a panel designed based on observations of genetic

658 diversity through WGS in countries A and B may not provide a fair means of comparing diversity in

659 countries $C$ vs. D, if diversity there is distributed differently in the genome than in countries $A$ and $B$.

660 WGS is the ultimate tool for avoiding this bias. However, the problems of comparing parasite populations

661 profiled with different panels may be mitigated by comparing inferred relatedness levels within

662 populations rather than actual genotypic diversity measures. Overlap of loci among panels would further

663 facilitate direct assessment of relatedness between samples included in different studies (Neafsey,

664 Taylor, \& Maclnnis, 2021; Taylor et al., 2019). The AMPLseq panel we describe here contains a

665 significant number $(n=47)$ of targets from the SpotMalaria panel, and we expect that future $P$. falciparum

666 panel designs will also tend to exhibit some degree of overlap with other panels, both by deliberate

667 design and through blind convergence based on key genomic features, such as high diversity and

668 sequence amenability to PCR primer design.

669 As molecular surveillance efforts for malaria and other diseases are more widely adopted and

670 become increasingly diverse, it will be essential for the community to develop standardized approaches

671 for the design, validation, interpretation, and sharing of targeted amplicon sequencing data. The

672 paneljudge R package described here provides an excellent means to comparatively evaluate existing

673 and hypothetical panel performance via data collected from previous population genomic surveys, and

674 the bioinformatic analysis pipelines we have developed are suitable for interpreting Illumina data from

675 diverse targets and panels in different organisms. We anticipate the growth of this field and the 
medRxiv preprint doi: https://doi.org/10.1101/2021.09.15.21263521; this version posted September 22, 2021. The copyright holder for this

preprint (which was not certified by peer review) is the author/funder, who has granted medRxiv a license to display the preprint in perpetuity.

It is made available under a CC-BY-NC-ND 4.0 International license .

676 development of new analytical tools to extract even more knowledge from increasingly large AmpSeq

677 datasets.

\section{Acknowledgments}

679 This project has been funded in whole or in part with Federal funds from the National Institute of

680 Allergy and Infectious Diseases, National Institutes of Health, Department of Health and Human

681 Services, under Grant Number U19AI110818 to the Broad Institute. This project was also supported by

682 an NIH R01 award to DN (R01Al141544), an award from the Bill and Melinda Gates Foundation to DN

683 and COB (OPP1213366), and a Broad Institute NextGen Award to BM. The Mali cohort study was

684 funded by the Division of Intramural Research, National Institute of Allergy and Infectious Diseases,

685 National Institutes of Health. The Colombian cohort study was supported by British Council

686 Newton-Caldas Fund Institutional Links Award G1854. We thank MalariaGen for use of the Colombian

687 WGS data. We thank Annie Laws for project management. We thank Dr. Nathan Campbell for assistance

688 in the AMPLseq panel design and evaluation.

\section{Data Accessibility and Benefit Sharing}

690 Data Accessibility: All amplicon sequencing data, as well as WGS data from 16 Guyana samples,

691 were submitted to the NCBI Sequence Read Archive (http://www.ncbi.nlm.nih.gov/sra) under accession

692 PRJNA758191. This publication uses data from the MalariaGEN Plasmodium falciparum Community

693 Project as described online pending publication and public release of dataset Pf7

694 (https://www.malariagen.net/resource/34); additional ENA accession numbers are available in Table S4.

695 Previously published data from Guyana and French Guiana can be found at SRA BioProjects

696 PRJNA543530 and PRJNA242182, respectively. Software and documentation can be found at

697 https://github.com/broadinstitute/AmpSeQC (AmpSeQC pipeline),

698 https://github.com/broadinstitute/malaria-amplicon-pipeline.git (Malaria amplicon pipeline), and

699 https://github.com/artaylor85/paneljudge (paneljudge).

700 Benefits Generated: A research collaboration was developed with scientists from the countries

701 providing genetic samples, all collaborators are included as co-authors, the results of research have 
medRxiv preprint doi: https://doi.org/10.1101/2021.09.15.21263521; this version posted September 22, 2021. The copyright holder for this preprint (which was not certified by peer review) is the author/funder, who has granted medRxiv a license to display the preprint in perpetuity.

It is made available under a CC-BY-NC-ND 4.0 International license .

702 been shared with the provider communities and the broader scientific community (see above), and the

703 research addresses a priority concern, in this case the public health concern of malaria. More broadly,

704 our group is committed to international scientific partnerships, as well as institutional capacity building.

\section{Author Contributions}

- Conceptualization EL, PS, MC, ART, AME, BLM, DEN

- Data Curation ZMJ, RP, TJS

- Formal Analysis EL, PS, MC, ART, RP, TJS

- Funding Acquisition COB, BLM, DEN

- Investigation PS, MC, ZMJ, MS, RK, SW

- Methodology EL, MC, PS, ART, ZMJ, MS, RP, TJS, RK

- Project Administration BLM, DEN

- Resources CMA, SP, PDC, BT, JCR, VC, KJ, HC

- Software ART, RP, TJS, AME

- Supervision COB, BLM, AME, DEN

- Validation EL, PS, MC, ZMJ, MS, RP, TJS, RK

- Visualization EL, PS, MC, ART, RP

- Writing - Original Draft Preparation EL, PS, MC, ART, DEN

- Writing - Review \& Editing [All authors] 


\section{References}

Ariey, F., Witkowski, B., Amaratunga, C., Beghain, J., Langlois, A.-C., Khim, N., Kim, S., Duru, V., Bouchier, C., Ma, L., Lim, P., Leang, R., Duong, S., Sreng, S., Suon, S., Chuor, C. M., Bout, D. M., Ménard, S., Rogers, W. O., ... Ménard, D. (2014). A molecular marker of artemisinin-resistant Plasmodium falciparum malaria. Nature, 505(7481), 50-55. https://doi.org/10.1038/nature12876

Aydemir, O., Janko, M., Hathaway, N. J., Verity, R., Mwandagalirwa, M. K., Tshefu, A. K., Tessema, S. K., Marsh, P. W., Tran, A., Reimonn, T., Ghani, A. C., Ghansah, A., Juliano, J. J., Greenhouse, B. R., Emch, M., Meshnick, S. R., \& Bailey, J. A. (2018). Drug-Resistance and Population Structure of Plasmodium falciparum Across the Democratic Republic of Congo Using High-Throughput Molecular Inversion Probes. The Journal of Infectious Diseases, 218(6), 946-955. https://doi.org/10.1093/infdis/jiy223

Baetscher, D. S., Clemento, A. J., Ng, T. C., Anderson, E. C., \& Garza, J. C. (2018). Microhaplotypes provide increased power from short-read DNA sequences for relationship inference. Molecular Ecology Resources, 18(2), 296-305. https://doi.org/10.1111/1755-0998.12737

Baker, S., Thomson, N., Weill, F.-X., \& Holt, K. E. (2018). Genomic insights into the emergence and spread of antimicrobial-resistant bacterial pathogens. Science, 360(6390), 733-738. https://doi.org/10.1126/science.aar3777

Baniecki, M. L., Faust, A. L., Schaffner, S. F., Park, D. J., Galinsky, K., Daniels, R. F., Hamilton, E., Ferreira, M. U., Karunaweera, N. D., Serre, D., Zimmerman, P. A., Sá, J. M., Wellems, T. E., Musset, L., Legrand, E., Melnikov, A., Neafsey, D. E., Volkman, S. K., Wirth, D. F., \& Sabeti, P. C. (2015). Development of a single nucleotide polymorphism barcode to genotype Plasmodium vivax infections. PLoS Neglected Tropical Diseases, 9(3), e0003539. https://doi.org/10.1371/journal.pntd.0003539

Callahan, B. J., McMurdie, P. J., Rosen, M. J., Han, A. W., Johnson, A. J. A., \& Holmes, S. P. (2016). DADA2: High-resolution sample inference from Illumina amplicon data. Nature Methods, 13(7), 581-583. https://doi.org/10.1038/nmeth.3869

Campbell, N. R., Harmon, S. A., \& Narum, S. R. (2015). Genotyping-in-Thousands by sequencing (GT-seq): A cost effective SNP genotyping method based on custom amplicon sequencing. Molecular Ecology Resources, 15(4), 855-867. https://doi.org/10.1111/1755-0998.12357

Cerqueira, G. C., Cheeseman, I. H., Schaffner, S. F., Nair, S., McDew-White, M., Phyo, A. P., Ashley, E. A., Melnikov, A., Rogov, P., Birren, B. W., Nosten, F., Anderson, T. J. C., \& Neafsey, D. E. (2017). Longitudinal genomic surveillance of Plasmodium falciparum malaria parasites reveals complex genomic architecture of emerging artemisinin resistance. Genome Biology, 18(1), 78. https://doi.org/10.1186/s13059-017-1204-4

Chang, H.-H., Wesolowski, A., Sinha, I., Jacob, C. G., Mahmud, A., Uddin, D., Zaman, S. I., Hossain, M. A., Faiz, M. A., Ghose, A., Sayeed, A. A., Rahman, M. R., Islam, A., Karim, M. J., Rezwan, M. K., Shamsuzzaman, A. K. M., Jhora, S. T., Aktaruzzaman, M. M., Drury, E., ... Buckee, C. (2019). Mapping imported malaria in Bangladesh using parasite genetic and human mobility data. ELife, 8, e43481. https://doi.org/10.7554/eLife.43481

Chang, H.-H., Worby, C. J., Yeka, A., Nankabirwa, J., Kamya, M. R., Staedke, S. G., Dorsey, G., Murphy, M., Neafsey, D. E., Jeffreys, A. E., Hubbart, C., Rockett, K. A., Amato, R., Kwiatkowski, D. P., Buckee, C. O., \& Greenhouse, B. (2017). THE REAL McCOIL: A method for the concurrent estimation of the complexity of infection and SNP allele frequency for malaria parasites. PLoS Computational Biology, 13(1), e1005348. https://doi.org/10.1371/journal.pcbi.1005348

Chenet, S. M., Akinyi Okoth, S., Huber, C. S., Chandrabose, J., Lucchi, N. W., Talundzic, E., Krishnalall, K., Ceron, N., Musset, L., Macedo de Oliveira, A., Venkatesan, M., Rahman, R., Barnwell, J. W., \& Udhayakumar, V. (2016). Independent Emergence of the Plasmodium falciparum Kelch Propeller Domain Mutant Allele C580Y in Guyana. The Journal of Infectious Diseases, 213(9), 1472-1475. https://doi.org/10.1093/infdis/jiv752

Chenet, S. M., Okoth, S. A., Kelley, J., Lucchi, N., Huber, C. S., Vreden, S., Macedo de Oliveira, A., Barnwell, J. W., Udhayakumar, V., \& Adhin, M. R. (2017). Molecular Profile of Malaria Drug Resistance Markers of Plasmodium falciparum in Suriname. Antimicrobial Agents and Chemotherapy, 61(7), e02655-16. https://doi.org/10.1128/AAC.02655-16

Coll, F., Harrison, E. M., Toleman, M. S., Reuter, S., Raven, K. E., Blane, B., Palmer, B., Kappeler, A. R. 
M., Brown, N. M., Török, M. E., Parkhill, J., \& Peacock, S. J. (2017). Longitudinal genomic surveillance of MRSA in the UK reveals transmission patterns in hospitals and the community. Science Translational Medicine, 9(413), eaak9745. https://doi.org/10.1126/scitrans/med.aak9745 Dalmat, R., Naughton, B., Kwan-Gett, T. S., Slyker, J., \& Stuckey, E. M. (2019). Use cases for genetic epidemiology in malaria elimination. Malaria Journal, 18(1), 1-11. https://doi.org/10.1186/s12936-019-2784-0

Danecek, P., Auton, A., Abecasis, G., Albers, C. A., Banks, E., DePristo, M. A., Handsaker, R. E., Lunter, G., Marth, G. T., Sherry, S. T., McVean, G., Durbin, R., \& 1000 Genomes Project Analysis Group. (2011). The variant call format and VCFtools. Bioinformatics, 27(15), 2156-2158. https://doi.org/10.1093/bioinformatics/btr330

Daniels, R. F., Schaffner, S. F., Wenger, E. A., Proctor, J. L., Chang, H.-H., Wong, W., Baro, N., Ndiaye, D., Fall, F. B., Ndiop, M., Ba, M., Milner, D. A., Taylor, T. E., Neafsey, D. E., Volkman, S. K., Eckhoff, P. A., Hartl, D. L., \& Wirth, D. F. (2015). Modeling malaria genomics reveals transmission decline and rebound in Senegal. Proceedings of the National Academy of Sciences of the United States of America, 112(22), 7067-7072. https://doi.org/10.1073/pnas.1505691112

Daniels, R., Volkman, S. K., Milner, D. A., Mahesh, N., Neafsey, D. E., Park, D. J., Rosen, D., Angelino, E., Sabeti, P. C., Wirth, D. F., \& Wiegand, R. C. (2008). A general SNP-based molecular barcode for Plasmodium falciparum identification and tracking. Malaria Journal, 7, 223. https://doi.org/10.1186/1475-2875-7-223

DePristo, M. A., Banks, E., Poplin, R., Garimella, K. V., Maguire, J. R., Hartl, C., Philippakis, A. A., del Angel, G., Rivas, M. A., Hanna, M., McKenna, A., Fennell, T. J., Kernytsky, A. M., Sivachenko, A. Y., Cibulskis, K., Gabriel, S. B., Altshuler, D., \& Daly, M. J. (2011). A framework for variation discovery and genotyping using next-generation DNA sequencing data. Nature Genetics, 43(5), 491-498. https://doi.org/10.1038/ng.806

Early, A. M., Daniels, R. F., Farrell, T. M., Grimsby, J., Volkman, S. K., Wirth, D. F., Maclnnis, B. L., \& Neafsey, D. E. (2019). Detection of low-density Plasmodium falciparum infections using amplicon deep sequencing. Malaria Journal, 18(1), 219. https://doi.org/10.1186/s12936-019-2856-1

Fidock, D. A., Nomura, T., Talley, A. K., Cooper, R. A., Dzekunov, S. M., Ferdig, M. T., Ursos, L. M., Sidhu, A. B., Naudé, B., Deitsch, K. W., Su, X. Z., Wootton, J. C., Roepe, P. D., \& Wellems, T. E. (2000). Mutations in the P. falciparum digestive vacuole transmembrane protein PfCRT and evidence for their role in chloroquine resistance. Molecular Cell, 6(4), 861-871. https://doi.org/10.1016/s1097-2765(05)00077-8

Fola, A. A., Kattenberg, E., Razook, Z., Lautu-Gumal, D., Lee, S., Mehra, S., Bahlo, M., Kazura, J., Robinson, L. J., Laman, M., Mueller, I., \& Barry, A. E. (2020). SNP barcodes provide higher resolution than microsatellite markers to measure Plasmodium vivax population genetics. Malaria Journal, 19(1), 375. https://doi.org/10.1186/s12936-020-03440-0

Galinsky, K., Valim, C., Salmier, A., de Thoisy, B., Musset, L., Legrand, E., Faust, A., Baniecki, M., Ndiaye, D., Daniels, R. F., Hartl, D. L., Sabeti, P. C., Wirth, D. F., Volkman, S. K., \& Neafsey, D. E. (2015). COIL: a methodology for evaluating malarial complexity of infection using likelihood from single nucleotide polymorphism data. Malaria Journal, 14(1), 4. https://doi.org/10.1186/1475-2875-14-4

Gamboa, D., Ho, M.-F., Bendezu, J., Torres, K., Chiodini, P. L., Barnwell, J. W., Incardona, S., Perkins, M., Bell, D., McCarthy, J., \& Cheng, Q. (2010). A Large Proportion of P. falciparum Isolates in the Amazon Region of Peru Lack pfhrp2 and pfhrp3: Implications for Malaria Rapid Diagnostic Tests. PloS One, 5(1). https://doi.org/10.1371/journal.pone.0008091

Gruenberg, M., Lerch, A., Beck, H.-P., \& Felger, I. (2019). Amplicon deep sequencing improves Plasmodium falciparum genotyping in clinical trials of antimalarial drugs. Scientific Reports, 9(1), 1-12. https://doi.org/10.1038/s41598-019-54203-0

Hargrove, J. S., McCane, J., Roth, C. J., High, B., \& Campbell, M. R. (2021). Mating systems and predictors of relative reproductive success in a Cutthroat Trout subspecies of conservation concern. Ecology and Evolution, 11(16). https://doi.org/10.1002/ece3.7914

Helb, D. A., Tetteh, K. K. A., Felgner, P. L., Skinner, J., Hubbard, A., Arinaitwe, E., Mayanja-Kizza, H., Ssewanyana, I., Kamya, M. R., Beeson, J. G., Tappero, J., Smith, D. L., Crompton, P. D., Rosenthal, P. J., Dorsey, G., Drakeley, C. J., \& Greenhouse, B. (2015). Novel serologic 
medRxiv preprint doi: https://doi.org/10.1101/2021.09.15.21263521; this version posted September 22, 2021. The copyright holder for this

preprint (which was not certified by peer review) is the author/funder, who has granted medRxiv a license to display the preprint in perpetuity.

It is made available under a CC-BY-NC-ND 4.0 International license .

biomarkers provide accurate estimates of recent Plasmodium falciparum exposure for individuals and communities. Proceedings of the National Academy of Sciences, 112(32), E4438-E4447. https://doi.org/10.1073/pnas.1501705112

Henden, L., Lee, S., Mueller, I., Barry, A., \& Bahlo, M. (2018). Identity-by-descent analyses for measuring population dynamics and selection in recombining pathogens. PLoS Genetics, 14(5), e1007279. https://doi.org/10.1371/journal.pgen.1007279

Jacob, C. G., Thuy-Nhien, N., Mayxay, M., Maude, R. J., Quang, H. H., Hongvanthong, B., Vanisaveth, V., Ngo Duc, T., Rekol, H., van der Pluijm, R., von Seidlein, L., Fairhurst, R., Nosten, F., Hossain, M. A., Park, N., Goodwin, S., Ringwald, P., Chindavongsa, K., Newton, P., ... Miotto, O. (2021). Genetic surveillance in the Greater Mekong subregion and South Asia to support malaria control and elimination. ELife, 10, e62997. https://doi.org/10.7554/eLife.62997

Jones, S., Kay, K., Hodel, E. M., Gruenberg, M., Lerch, A., Felger, I., \& Hastings, I. (2021). Should deep-sequenced amplicons become the new gold-standard for analysing malaria drug clinical trials? Antimicrobial Agents and Chemotherapy, AAC0043721. https://doi.org/10.1128/AAC.00437-21

Kayiba, N. K., Yobi, D. M., Tshibangu-Kabamba, E., Tuan, V. P., Yamaoka, Y., Devleesschauwer, B., Mvumbi, D. M., Okitolonda Wemakoy, E., De Mol, P., Mvumbi, G. L., Hayette, M.-P., Rosas-Aguirre, A., \& Speybroeck, N. (2021). Spatial and molecular mapping of Pfkelch13 gene polymorphism in Africa in the era of emerging Plasmodium falciparum resistance to artemisinin: a systematic review. The Lancet. Infectious Diseases, 21(4), e82-e92. https://doi.org/10.1016/S1473-3099(20)30493-X

Knudson, A., González-Casabianca, F., Feged-Rivadeneira, A., Pedreros, M. F., Aponte, S., Olaya, A., Castillo, C. F., Mancilla, E., Piamba-Dorado, A., Sanchez-Pedraza, R., Salazar-Terreros, M. J., Lucchi, N., Udhayakumar, V., Jacob, C., Pance, A., Carrasquilla, M., Apráez, G., Angel, J. A., Rayner, J. C., \& Corredor, V. (2020). Spatio-temporal dynamics of Plasmodium falciparum transmission within a spatial unit on the Colombian Pacific Coast. Scientific Reports, 10(1), 3756. https://doi.org/10.1038/s41598-020-60676-1

Krijthe, J. H. (2015). Rtsne: T-Distributed Stochastic Neighbor Embedding using a Barnes-Hut Implementation. https://github.com/jkrijthe/Rtsne

Lautu-Gumal, D., Razook, Z., Koleala, T., Nate, E., McEwen, S., Timbi, D., Hetzel, M. W., Lavu, E., Tefuarani, N., Makita, L., Kazura, J., Mueller, I., Pomat, W., Laman, M., Robinson, L. J., \& Barry, A. E. (2021). Surveillance of molecular markers of Plasmodium falciparum artemisinin resistance (kelch13 mutations) in Papua New Guinea between 2016 and 2018. International Journal for Parasitology. Drugs and Drug Resistance, 16, 188-193. https://doi.org/10.1016/j.ijpddr.2021.06.004

Lefterova, M. I., Budvytiene, I., Sandlund, J., Färnert, A., \& Banaei, N. (2015). Simple real-time PCR and amplicon sequencing method for identification of plasmodium species in human whole blood. Journal of Clinical Microbiology, 53(7), 2251-2257. https://doi.org/10.1128/JCM.00542-15

Lerch, A., Koepfli, C., Hofmann, N. E., Messerli, C., Wilcox, S., Kattenberg, J. H., Betuela, I., O'Connor, L., Mueller, I., \& Felger, I. (2017). Development of amplicon deep sequencing markers and data analysis pipeline for genotyping multi-clonal malaria infections. BMC Genomics, 18(1), 864. https://doi.org/10.1186/s12864-017-4260-y

$\mathrm{Li}, \mathrm{H}$. (2013). Aligning sequence reads, clone sequences and assembly contigs with BWA-MEM. ArXiv:1303.3997 [Preprint]. http://arxiv.org/abs/1303.3997

Liu, Y., Tessema, S. K., Murphy, M., Xu, S., Schwartz, A., Wang, W., Cao, Y., Lu, F., Tang, J., Gu, Y., Zhu, G., Zhou, H., Gao, Q., Huang, R., Cao, J., \& Greenhouse, B. (2020). Confirmation of the absence of local transmission and geographic assignment of imported falciparum malaria cases to China using microsatellite panel. Malaria Journal, 19(1), 244. https://doi.org/10.1186/s12936-020-03316-3

MalariaGEN Plasmodium falciparum Community Project. (2016). Genomic epidemiology of artemisinin resistant malaria. ELife, 5, e08714. https://doi.org/10.7554/eLife.08714

Mathieu, L. C., Cox, H., Early, A. M., Mok, S., Lazrek, Y., Paquet, J.-C., Ade, M.-P., Lucchi, N. W., Grant, Q., Udhayakumar, V., Alexandre, J. S., Demar, M., Ringwald, P., Neafsey, D. E., Fidock, D. A., \& Musset, L. (2020). Local emergence in Amazonia of Plasmodium falciparum k13 C580Y mutants 
associated with in vitro artemisinin resistance. ELife, 9, e51015. https://doi.org/10.7554/eLife.51015

McKenna, A., Hanna, M., Banks, E., Sivachenko, A., Cibulskis, K., Kernytsky, A., Garimella, K., Altshuler, D., Gabriel, S., Daly, M., \& DePristo, M. A. (2010). The Genome Analysis Toolkit: a MapReduce framework for analyzing next-generation DNA sequencing data. Genome Research, 20(9), 1297-1303. https://doi.org/10.1101/gr.107524.110

Miles, A., Iqbal, Z., Vauterin, P., Pearson, R., Campino, S., Theron, M., Gould, K., Mead, D., Drury, E., O’Brien, J., Rubio, V. R., MacInnis, B., Mwangi, J., Samarakoon, U., Ranford-Cartwright, L., Ferdig, M., Hayton, K., Su, X., Wellems, T., ... Kwiatkowski, D. (2016). Indels, structural variation, and recombination drive genomic diversity in Plasmodium falciparum. Genome Research, 26(9), 1288-1299. https://doi.org/10.1101/gr.203711.115

Miles, A., pyup.io bot, Murillo, R., Ralph, P., Harding, N. J., Rahul Pisupati, Summer Rae, \& Tim Millar. (2020). cggh/scikit-allel: v1.3.2. Zenodo. https://doi.org/10.5281/zenodo.3976233

Miller, R. H., Hathaway, N. J., Kharabora, O., Mwandagalirwa, K., Tshefu, A., Meshnick, S. R., Taylor, S. M., Juliano, J. J., Stewart, V. A., \& Bailey, J. A. (2017). A deep sequencing approach to estimate Plasmodium falciparum complexity of infection (COI) and explore apical membrane antigen 1 diversity. Malaria Journal, 16(1), 490. https://doi.org/10.1186/s12936-017-2137-9

Miotto, O., Amato, R., Ashley, E. A., MacInnis, B., Almagro-Garcia, J., Amaratunga, C., Lim, P., Mead, D., Oyola, S. O., Dhorda, M., Imwong, M., Woodrow, C., Manske, M., Stalker, J., Drury, E., Campino, S., Amenga-Etego, L., Thanh, T.-N. N., Tran, H. T., ... Kwiatkowski, D. P. (2015). Genetic architecture of artemisinin-resistant Plasmodium falciparum. Nature Genetics, 47(3), 226-234. https://doi.org/10.1038/ng.3189

Miotto, O., Sekihara, M., Tachibana, S.-I., Yamauchi, M., Pearson, R. D., Amato, R., Gonçalves, S., Mehra, S., Noviyanti, R., Marfurt, J., Auburn, S., Price, R. N., Mueller, I., Ikeda, M., Mori, T., Hirai, M., Tavul, L., Hetzel, M. W., Laman, M., ... Mita, T. (2020). Emergence of artemisinin-resistant Plasmodium falciparum with kelch13 C580Y mutations on the island of New Guinea. PLoS Pathogens, 16(12), e1009133. https://doi.org/10.1371/journal.ppat.1009133

Mita, T., Tanabe, K., Takahashi, N., Tsukahara, T., Eto, H., Dysoley, L., Ohmae, H., Kita, K., Krudsood, S., Looareesuwan, S., Kaneko, A., Björkman, A., \& Kobayakawa, T. (2007). Independent Evolution of Pyrimethamine Resistance in Plasmodium falciparum Isolates in Melanesia. Antimicrobial Agents and Chemotherapy, 51(3), 1071-1077. https://doi.org/10.1128/AAC.01186-06

Mitchell, R. M., Zhou, Z., Sheth, M., Sergent, S., Frace, M., Nayak, V., Hu, B., Gimnig, J., ter Kuile, F., Lindblade, K., Slutsker, L., Hamel, M. J., Desai, M., Otieno, K., Kariuki, S., Vigfusson, Y., \& Shi, Y. P. (2021). Development of a new barcode-based, multiplex-PCR, next-generation-sequencing assay and data processing and analytical pipeline for multiplicity of infection detection of Plasmodium falciparum. Malaria Journal, 20(1), 92. https://doi.org/10.1186/s12936-021-03624-2

Moser, K. A., Madebe, R. A., Aydemir, O., Chiduo, M. G., Mandara, C. I., Rumisha, S. F., Chaky, F., Denton, M., Marsh, P. W., Verity, R., Watson, O. J., Ngasala, B., Mkude, S., Molteni, F., Njau, R., Warsame, M., Mandike, R., Kabanywanyi, A. M., Mahende, M. K., ... Bailey, J. A. (2021). Describing the current status of Plasmodium falciparum population structure and drug resistance within mainland Tanzania using molecular inversion probes. Molecular Ecology, 30(1), 100-113. https://doi.org/10.1111/mec.15706

Natesh, M., Taylor, R. W., Truelove, N. K., Hadly, E. A., Palumbi, S. R., Petrov, D. A., \& Ramakrishnan, U. (2019). Empowering conservation practice with efficient and economical genotyping from poor quality samples. Methods in Ecology and Evolution, 10(6), 853-859. https://doi.org/10.1111/2041-210X.13173

Neafsey, D. E., Juraska, M., Bedford, T., Benkeser, D., Valim, C., Griggs, A., Lievens, M., Abdulla, S., Adjei, S., Agbenyega, T., Agnandji, S. T., Aide, P., Anderson, S., Ansong, D., Aponte, J. J., Asante, K. P., Bejon, P., Birkett, A. J., Bruls, M., ... Wirth, D. F. (2015). Genetic Diversity and Protective Efficacy of the RTS,S/AS01 Malaria Vaccine. New England Journal of Medicine, 373(21), 2025-2037. https://doi.org/10.1056/NEJMoa1505819

Neafsey, D. E., Taylor, A. R., \& Maclnnis, B. L. (2021). Advances and opportunities in malaria population genomics. Nature Reviews. Genetics. https://doi.org/10.1038/s41576-021-00349-5 
936 Nelson, C. S., Sumner, K. M., Freedman, E., Saelens, J. W., Obala, A. A., Mangeni, J. N., Taylor, S. M., \& O'Meara, W. P. (2019). High-resolution micro-epidemiology of parasite spatial and temporal dynamics in a high malaria transmission setting in Kenya. Nature Communications, 10, 5615. https://doi.org/10.1038/s41467-019-13578-4

Oude Munnink, B. B., Worp, N., Nieuwenhuijse, D. F., Sikkema, R. S., Haagmans, B., Fouchier, R. A. M., \& Koopmans, M. (2021). The next phase of SARS-CoV-2 surveillance: real-time molecular epidemiology. Nature Medicine. https://doi.org/10.1038/s41591-021-01472-w

Oyola, S. O., Ariani, C. V., Hamilton, W. L., Kekre, M., Amenga-Etego, L. N., Ghansah, A., Rutledge, G. G., Redmond, S., Manske, M., Jyothi, D., Jacob, C. G., Otto, T. D., Rockett, K., Newbold, C. I., Berriman, M., \& Kwiatkowski, D. P. (2016). Whole genome sequencing of Plasmodium falciparum from dried blood spots using selective whole genome amplification. Malaria Journal, 15(1). https://doi.org/10.1186/s12936-016-1641-7

Pelleau, S., Moss, E. L., Dhingra, S. K., Volney, B., Casteras, J., Gabryszewski, S. J., Volkman, S. K., Wirth, D. F., Legrand, E., Fidock, D. A., Neafsey, D. E., \& Musset, L. (2015). Adaptive evolution of malaria parasites in French Guiana: Reversal of chloroquine resistance by acquisition of a mutation in pfcrt. Proceedings of the National Academy of Sciences, 112(37), 11672-11677. https://doi.org/10.1073/pnas.1507142112

Quick, J., Loman, N. J., Duraffour, S., Simpson, J. T., Severi, E., Cowley, L., Bore, J. A., Koundouno, R., Dudas, G., Mikhail, A., Ouédraogo, N., Afrough, B., Bah, A., Baum, J. H. J., Becker-Ziaja, B., Boettcher, J. P., Cabeza-Cabrerizo, M., Camino-Sánchez, Á., Carter, L. L., ... Carroll, M. W. (2016). Real-time, portable genome sequencing for Ebola surveillance. Nature, 530(7589), 228-232. https://doi.org/10.1038/nature16996

Reeder, J. C., \& Marshall, V. M. (1994). A simple method for typing Plasmodium falciparum merozoite surface antigens 1 and 2 (MSA-1 and MSA-2) using a dimorphic-form specific polymerase chain reaction. Molecular and Biochemical Parasitology, 68(2), 329-332. https://doi.org/10.1016/0166-6851(94)90179-1

Ruybal-Pesántez, S., Sáenz, F. E., Deed, S., Johnson, E. K., Larremore, D. B., Vera-Arias, C. A., Tiedje, K. E., \& Day, K. P. (2021). Clinical malaria incidence following an outbreak in Ecuador was predominantly associated with Plasmodium falciparum with recombinant variant antigen gene repertoires. MedRxiv [Preprint], 2021.04.12.21255093. https://doi.org/10.1101/2021.04.12.21255093

Schaffner, S. F., Taylor, A. R., Wong, W., Wirth, D. F., \& Neafsey, D. E. (2018). hmmIBD: software to infer pairwise identity by descent between haploid genotypes. Malaria Journal, 17(1), 196. https://doi.org/10.1186/s12936-018-2349-7

Schmidt, D. A., Campbell, N. R., Govindarajulu, P., Larsen, K. W., \& Russello, M. A. (2020). Genotyping-in-Thousands by sequencing (GT-seq) panel development and application to minimally invasive DNA samples to support studies in molecular ecology. Molecular Ecology Resources, 20(1), 114-124. https://doi.org/10.1111/1755-0998.13090

Schwabl, P., Maiguashca Sánchez, J., Costales, J. A., Ocaña-Mayorga, S., Segovia, M., Carrasco, H. J., Hernández, C., Ramírez, J. D., Lewis, M. D., Grijalva, M. J., \& Llewellyn, M. S. (2020). Culture-free genome-wide locus sequence typing (GLST) provides new perspectives on Trypanosoma cruzi dispersal and infection complexity. PLoS Genetics, 16(12), e1009170. https://doi.org/10.1371/journal.pgen.1009170

Snounou, G. (2002). Genotyping of Plasmodium spp. Nested PCR. Methods in Molecular Medicine, 72, 103-116. https://doi.org/10.1385/1-59259-271-6:103

Takala-Harrison, S., Jacob, C. G., Arze, C., Cummings, M. P., Silva, J. C., Dondorp, A. M., Fukuda, M. M., Hien, T. T., Mayxay, M., Noedl, H., Nosten, F., Kyaw, M. P., Nhien, N. T. T., Imwong, M., Bethell, D., Se, Y., Lon, C., Tyner, S. D., Saunders, D. L., ... Plowe, C. V. (2015). Independent emergence of artemisinin resistance mutations among Plasmodium falciparum in Southeast Asia. The Journal of Infectious Diseases, 211(5), 670-679. https://doi.org/10.1093/infdis/jiu491

Taylor, A. R., \& Jacob, P. E. (2020). paneljudge: Judge the performance of a panel of genetic markers using simulated data. (R package version 0.0.0.9000) [Computer software].

Taylor, A. R., Jacob, P. E., Neafsey, D. E., \& Buckee, C. O. (2019). Estimating Relatedness Between Malaria Parasites. Genetics, 212(4), 1337-1351. https://doi.org/10.1534/genetics.119.302120 
990 Taylor, A. R., Schaffner, S. F., Cerqueira, G. C., Nkhoma, S. C., Anderson, T. J. C., Sriprawat, K., Pyae

991

992

993

994

995

996

997

998

999

1001

1002

1003

1004

1005

1006

1007

1008

1009

1010

1011 T

1012

1013

1014

1015

1016

1017 Van der Auwera, G. A., Carneiro, M. O., Hartl, C., Poplin, R., Del Angel, G., Levy-Moonshine, A., Jordan,

1018 T., Shakir, K., Roazen, D., Thibault, J., Banks, E., Garimella, K. V., Altshuler, D., Gabriel, S., \&

1019 DePristo, M. A. (2013). From FastQ data to high confidence variant calls: the Genome Analysis

1020

1021

1022

1023

1024

1025

1026 WHO. (2019). World Malaria Report. https://www.who.int/publications-detail/world-malaria-report-2019

1027 Zhu, S. J., Hendry, J. A., Almagro-Garcia, J., Pearson, R. D., Amato, R., Miles, A., Weiss, D. J., Lucas, T.

1028

1029

1030
C., Nguyen, M., Gething, P. W., Kwiatkowski, D., McVean, G., \& for the Pf3k Project. (2019). The origins and relatedness structure of mixed infections vary with local prevalence of $P$. falciparum malaria. ELife, 8. https://doi.org/10.7554/eLife.40845 